This document is the accepted manuscript version of the following article:

Bamberger, I., Oney, B., Brunner, D., Henne, S., Leuenberger, M., Buchmann, N., \& Eugster, W. (2017).

observations of atmospheric methane and carbon dioxide mixing ratios: tal1-tower or mountain-top stations?

Boundary-Layer Meteorology, 164(1), 135-159. https://doi.org/10.1007/s10546-017-0236-3

1 Observations of Atmospheric Methane and Carbon Dioxide

2 Mixing Ratios: Tall-tower or Mountain-top Stations?

3

4 Ines Bamberger • Brian Oney • Dominik Brunner • Stephan Henne • Markus

5 Leuenberger • Nina Buchmann • Werner Eugster

Received: DD Month 2015/ Accepted: DD Month YEAR

10 Abstract Mountain-top observations of greenhouse gas mixing ratios may be an

11 alternative to tall-tower measurements for regional scale source and sink estimation. To

12 investigate the equivalence or limitations of a mountain-top site as compared to a tall

13 tower site, we used the unique opportunity of comparing in situ measurements of

14 methane $\left(\mathrm{CH}_{4}\right)$ and carbon dioxide $\left(\mathrm{CO}_{2}\right)$ mixing ratios at a mountain top (986 $\mathrm{m}$ above

15 sea level, a.s.1.) with measurements from a nearby (distance $28.4 \mathrm{~km}$ ) tall tower, sampled

16 at almost the same elevation (1009 m a.s.1.). Special attention was given to (i) how local

17 wind statistics and greenhouse gas sources and sinks at the mountain top influence the

18 observations, and (ii) whether mountain-top observations can be used as for those from a

19 tall tower for constraining regional greenhouse gas emissions. Wind statistics at the

20 mountain-top site are clearly more influenced by local flow systems than those at the tall-

21 tower site. Differences in temporal patterns of the greenhouse gas mixing ratios observed

22 at the two sites are mostly related to the influence of local sources and sinks at the

Ines Bamberger • Nina Buchmann • Werner Eugster

Department of Environmental Systems Science, Institute of Agricultural Sciences, ETH Zurich,

Switzerland.

e-mail: \{ines.bamberger@kit.edu\}, \{eugsterw@ethz.ch\}

Present Address

Ines Bamberger

Institute of Meteorology and Climate Research Atmospheric Environmental Research (IMK-IFU),

Karlsruhe Institute of Technology (KIT), Campus Alpin, Garmisch-Partenkirchen, Germany

Brian Oney • Dominik Brunner • Stephan Henne

Empa, Swiss Federal Laboratories for Materials Science and Technology, Duebendorf,

Switzerland. 
23 mountain top site. Major influences of local sources can be removed by applying a 24 statistical filter $\left(5^{\text {th }}\right.$ percentile) or a filter that removes periods with unfavourable flow

25 conditions. In the best case, the bias in mixing ratios between the mountain-top and the 26 tall-tower sites after the application of the wind filter was $27-0.0005 \pm 0.0010 \mathrm{ppm}$ for methane (September, 0000-0400 UTC) and $0.11 \pm 0.18 \mathrm{ppm}$ 28 for $\mathrm{CO}_{2}$ (February, 1200-1600 UTC). Temporal fluctuations of atmospheric $\mathrm{CH}_{4}$ and $29 \mathrm{CO}_{2}$ mixing ratios at both stations also showed good agreement (apart from $\mathrm{CO}_{2}$ during 30 summertime) as determined by moving bi-weekly Pearson correlation coefficients (up to 310.96 for $\mathrm{CO}_{2}$ and 0.97 for $\mathrm{CH}_{4}$ ). When only comparing mixing ratios minimally 32 influenced by local sources (low bias and high correlation coefficients), our 33 measurements indicate that mountain-top observations are comparable to tall-tower 34 observations.

36 Keywords Atmospheric observations • Greenhouse gases • Local greenhouse gas sources $37 \cdot$ Mountain meteorology $\cdot$ Mountain top $\cdot$ Tall tower

\section{Introduction}

40 Tall-tower measurements of atmospheric greenhouse gases contain information from

41 larger spatial scales than measurements close to the ground (Marquis and Tans 2008) and 42 thus provide valuable information for resolving regional transport and the distribution of 43 greenhouse gases (Gloor et al., 2001). In contrast, greenhouse gas mixing ratios measured 44 at mountain-top stations are often more influenced by boundary-layer processes and by 45 local sources and sinks than are tall-tower measurements. This is mainly due to the 46 complex topography around mountain sites and the low sampling height above the 47 ground, allowing local fluxes to considerably influence the local concentration field. To 48 address the question: how similar, or how different, are mountain-top and tall-tower 49 measurements at the same elevation above sea level, we compared carbon dioxide $\left(\mathrm{CO}_{2}\right)$ 50 and methane $\left(\mathrm{CH}_{4}\right)$ mixing ratio measurements at a mountain-top and a tall-tower site 51 that are only separated by $28.4 \mathrm{~km}$, which allows for a unique and direct comparison. It is 52 not expected that short-term variations at two sites separated by such a distance are 53 synchronous, but it can be expected that, with adequate statistical aggregation, 
54 measurements made at both sites should provide similar regional information in the $\mathrm{CO}_{2}$ 55 and $\mathrm{CH}_{4}$ time series.

56 While the global budgets of carbon dioxide and methane are relatively well known, their

57 sources and sinks are poorly constrained based on current regional scale observational 58 networks, where "regional" used herein refers to an area $>10^{4} \mathrm{~km}^{2}$ (Cleugh et al. 2004).

59 With a joint contribution of $81 \%$ to the positive anthropogenic radiative forcing, $\mathrm{CO}_{2}$

60 and $\mathrm{CH}_{4}$ are the two most important anthropogenic greenhouse gases (Myhre et al. 2013).

61 Even though tall-tower networks in both Europe and North America provide observations

62 of net changes in $\mathrm{CO}_{2}$ and $\mathrm{CH}_{4}$ mixing ratios at large spatial scales, the network density

63 is insufficient to resolve atmospheric and surface flux patterns at the smaller regional

64 (sub-national) scale (Marquis and Tans 2008, Villani et al. 2010, Dlugokencky et al.

65 2011). An increased number of tall-tower stations would be beneficial for resolving the

66 regional distribution of greenhouse gas mixing ratios (Lauvaux et al. 2012). A

67 concentrated effort towards a dense regional network of tall towers was initiated by the

68 NOAA Earth System Research Laboratory that resulted in a network of seven towers

69 (Andrews et al. 2014). Similarly in Europe, a tall tower network exists with seven towers

70 (e.g., Vermeulen et al. 2011, Thompson et al. 2009), and in order to expand existing and

71 create new networks, TV and radio broadcasting towers could be equipped with relevant

72 instrumentation (Marquis and Tans 2008, Andrews et al. 2014). Such towers and

73 additional sites are currently being integrated into the European Integrated Carbon

74 Observation System (ICOS, www.icos-ri.eu). However, access to existing 75 telecommunication towers may not always be possible, and the installation and 76 maintenance of measurement instrumentation is often prohibitive and time intensive.

77 Other approaches such as aircraft measurements (e.g., Beck et al. 2012, Schuck et al. 78 2012, Xiong et al. 2010) yield useful snapshots of the atmospheric composition and add 79 supplementary information on vertical and horizontal profiles (Crevoisier et al. 2006, 80 Zhang et al. 2014). Long-term aircraft measurements of greenhouse gases within the 81 NOAA atmospheric monitoring network have been carried out by Karion et al. (2013) 82 twice a week over selected areas, but such airborne measurements cannot provide 83 continuous, long-term observations, and may miss essential parts of the atmospheric 84 variability, especially on the regional scale. Remote sensing products such as satellite 
85 retrievals of global atmospheric greenhouse gas total column mixing ratios have recently

86 become available (Frankenberg et al. 2005, 2008, 2015, Kuze et al. 2009, Buchwitz et al.

87 2013). These measurements are complementary in their ability to provide spatial

88 information on atmospheric greenhouse gases. However, they are still limited in their

89 temporal and spatial resolutions, are affected by cloud cover, and are less accurate and

90 less sensitive to surface fluxes than in situ measurements (Marquis and Tans 2008).

91 Alternatively, continuous measurements of $\mathrm{CO}_{2}$ and $\mathrm{CH}_{4}$ mixing ratios close to the

92 ground but at elevated locations such as mountain tops might provide a footprint of

93 similar size as that of a tall-tower station. Consequently, the use of such measurement

94 stations could complement the number of sites used to measure greenhouse gas mixing

95 ratios, especially in mountainous regions where tower facilities are rare (Andrews et al.

96 2014, Lee et al. 2015). However, to the best of our knowledge, the comparability of

97 mountain-top data to tall-tower data in a direct comparison, as we present here, has not

98 yet been investigated. Greenhouse gas mixing ratios at mountain tops might be

99 influenced by local flows and nearby greenhouse gas sources and sinks. All these

100 influences may negatively affect the regional representativeness of mountain top

101 measurements (Brooks et al. 2012). Before being used in atmospheric inversions,

102 mountain-top measurements may need to be screened using meteorological or statistical

103 filters in order to remove local influences (Brooks et al. 2012, Lee et al. 2015).

104 Highly accurate atmospheric mixing ratio measurements in combination with an inverse 105 transport model are required to produce quantitative information on greenhouse gas 106 sources and sinks (Nisbet and Weiss 2010). Thus, apart from network density and 107 accuracy of measurements, the top-down approach to determining regional and global 108 greenhouse gas fluxes is dependent on the reliability of transport models to allocate 109 regional sources and sinks (Lin and Gerbig 2005, Gerbig et al. 2008, Tolk et al. 2008,

110 Kretschmer et al. 2014). Even if measurements are taken at considerable altitudes above 111 ground, the exact representation of the transport of greenhouse gases may be a major 112 source of uncertainty in these top-down approaches (e.g., McKain et al. 2012, Smallman 113 et al. 2014). Especially due to the development of small-scale local circulations, such as 114 thermally induced slope-wind systems (Whiteman 2000) and their insufficient 115 representation in relatively coarse-resolution atmospheric transport models, the 
116 greenhouse gas mixing ratios above complex terrain (e.g. mountain tops) are difficult to

117 predict using such models. Subgrid-scale transport processes due to complex topography

118 are currently not, or only very crudely, represented in global and regional-scale transport

119 models (van der Molen and Dolman 2007, Tolk et al. 2008) that are used for estimating

120 greenhouse gas fluxes at continental to global scales. Recently it has been argued that the

121 use of such coarse transport models results in an underestimation of net $\mathrm{CO}_{2}$ exchange

122 (Rotach et al. 2013), which is critical since at least $50 \%$ of the land surface can be

123 classified as complex terrain (Rotach et al. 2007, 2013). Thus, in combination with

124 measurements in complex terrain (e.g. at mountain tops), high-resolution transport

125 models are required to capture micro scale to meso scale (2 to $20 \mathrm{~km}$ ) wind circulations

126 and their effect on greenhouse gas mixing ratios (Pillai et al. 2011). Another drawback of

127 mountain-top measurements may be that they are affected by microscale greenhouse gas

128 sources or sinks, close to the measurement inlet that cannot readily be represented in a

129 transport model. Thus, it is unclear how local sources and local flows will influence

130 greenhouse gas mixing ratios observed at a mountain-top station as compared to a tall-

131 tower station.

132 The aim of this study is to determine whether a mountain-top station can provide data of

133 similar quality as those at a tall-tower station. For this purpose, we compared $\mathrm{CO}_{2}$ and

$134 \mathrm{CH}_{4}$ mixing ratio measurements at sub-daily to seasonal time scales from a tall-tower and

135 a mountain-top station in Switzerland, located at a similar elevation (above sea level) and

136 with a relatively short horizontal distance from each other $(28.4 \mathrm{~km})$. The two sites are

137 part of a greenhouse gas observation network in Switzerland that has recently been

138 established in the framework of the CarboCount $\mathrm{CH}$ project (www.carbocount.ch, Oney

139 et al. 2015).

140 We pose the following questions: (1) How different are flows at the mountain-top

141 compared to the tall-tower stations? (2) How important is the potential contamination of

142 the mountain-top measurements by local greenhouse gas sources and sinks if an inlet

143 close to the ground is used? (3) Is it possible to identify optimum atmospheric conditions

144 for which mountain-top observations are comparable to those from a tall tower, given that

145 other environmental factors are similar (i.e. climate, distance to pollution from urban 146 centres)? 


\section{Materials and Methods}

\section{$150 \quad 2.1$ Field Sites}

151 Measurements of greenhouse gases and meteorological variables were made at two of the 152 four sites of the CarboCount $\mathrm{CH}$ observation network in Switzerland, which has been 153 established to investigate greenhouse gas sources and sinks through an integrated 154 approach using both observations and atmospheric transport models (Oney et al. 2015). 155 The two sites are located within $28.4 \mathrm{~km}$ of each other close to the southern edge of the 156 Swiss Plateau, the relatively flat, most densely populated and agriculturally used area in 157 Switzerland, located between the Alps and the Jura mountains. A cross-sectional profile 158 of the topography between both stations and photographs of the corresponding sites are 159 shown in Fig. 1. The proximity of both sites guaranteed comparable weather conditions 160 as well as a similar distance to major greenhouse gas sources and sinks.

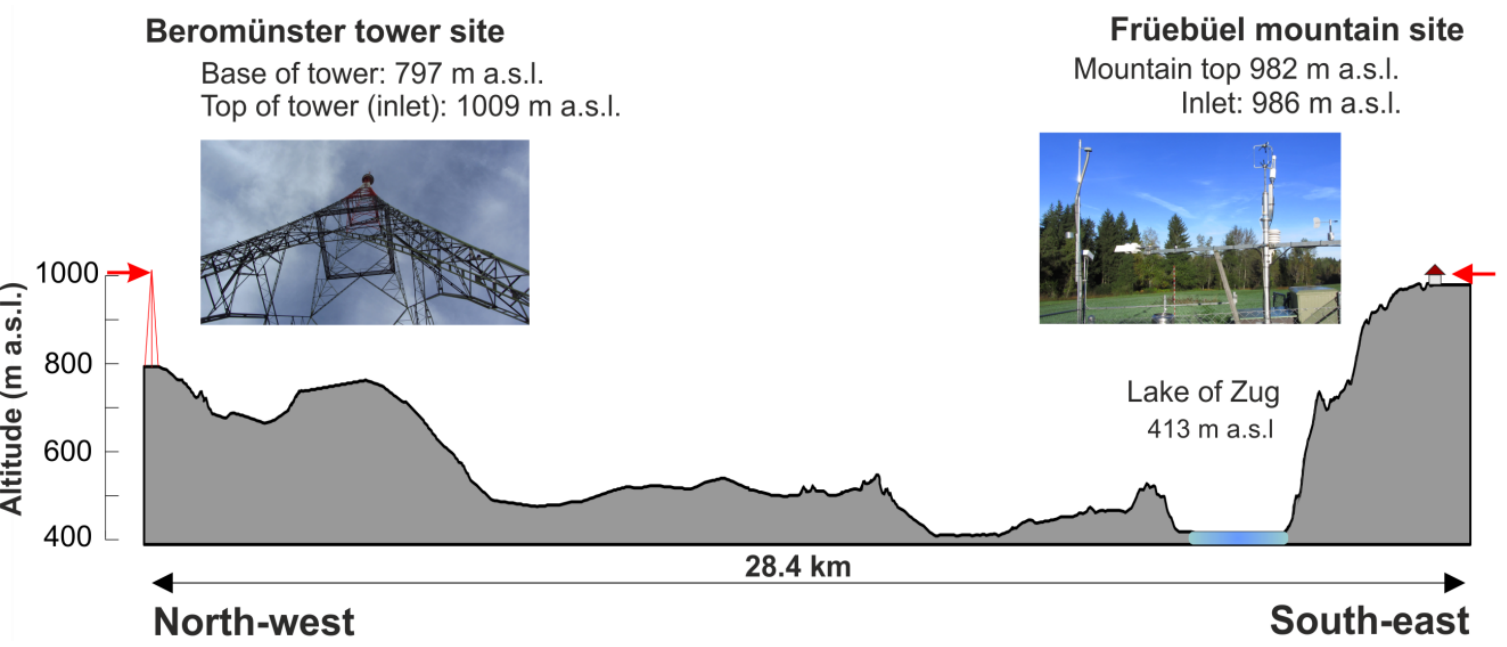

162 Fig. 1 Topographical transect between the tall-tower site Beromünster (left) and the mountain-top site

163 Früebüel (right). Red arrows indicate the inlet heights at both sites. Note the vertical amplification of the 164 scale.

\subsubsection{Früebüel Mountain-top Station}

167 Measurements at Früebüel - a Swiss FluxNet site (www.swissfluxnet.ch) - were taken on 168 top of the Zugerberg mountain ridge, located at an elevation of $982 \mathrm{~m}$ above sea level 
169 (a.s.l.) in the pre-alpine foothills of Switzerland $\left(47^{\circ} 06^{\prime} 57.0^{\prime \prime} \mathrm{N}, 8^{\circ} 32^{\prime} 16.0^{\prime \prime} \mathrm{E}\right)$. The site is

170 located on a relatively flat highland, extending about $2 \mathrm{~km}$ in the east-west and $5 \mathrm{~km}$ in

171 the north-south directions, and is thus not a classical mountain-top site because it has no

172 pronounced peak. Average daytime convective boundary-layer heights above the Swiss

173 Plateau usually exceed $500 \mathrm{~m}$ above the ground during the warm season (March to

174 September, Collaud Coen et al. 2014). With an elevation of $1000 \mathrm{~m}(\approx 500 \mathrm{~m}$ above the

175 Swiss Plateau) we therefore assume that Früebüel mostly lies within the convective

176 boundary layer.

177 The Zugerberg mountain ridge is a sparsely populated agricultural area, with prevailing

178 land-cover types managed grasslands and forests. The towns of $\mathrm{Zug}$ (at $\approx 10 \mathrm{~km}$ distance)

179 and Lucerne $(\approx 20 \mathrm{~km})$ are the nearest larger towns and are situated approximately $180450 \mathrm{~m}$ below the measurement station's elevation.

181 The air inlet for the greenhouse gas mixing ratio measurements was installed $4 \mathrm{~m}$ above a 182 moderately intensively managed grassland (Zeeman et al. 2010, Imer et al. 2013), with 183 meteorological measurements (wind speed, air temperature) taken approximately $3 \mathrm{~m}$ 184 away from the air inlet at 2-m height. In 2013, the average air temperature was $7.1^{\circ} \mathrm{C}$, 185 ranging from $-14.5^{\circ} \mathrm{C}$ to $34.8^{\circ} \mathrm{C}$ (range of 2-h averages).

186 Farmsteads and barns of the ETH (Eidgenössische Technische Hochschule) research 187 station Früebüel are located approximately $300 \mathrm{~m}$ to the south-west of the atmospheric 188 measurement tower. In 2013, the farmstead accommodated between 96 (June) and 50 189 (December) head of cattle, and from October till mid-November an additional 15 sheep. 190 From mid-July to mid-September all cattle were relocated to remote alpine pastures off 191 site. Otherwise, there were no other farmsteads or other anthropogenic sources in close 192 vicinity to the site. The three grassland parcels directly adjacent to the station were 193 managed differently; while the ungrazed meadow next to the measurement station was 194 cut three times and fertilized twice a year, the two grazed parcels were only fertilized 195 once and cut once or twice a year (Table S1 in Supplementary Material). 
198 The Beromünster tall-tower station is located approximately $30 \mathrm{~km}$ to the west of 199 Früebüel, atop a gentle hill (797 m a.s.1., $\left.47^{\circ} 11^{\prime} 22.4^{\prime \prime} \mathrm{N}, 8^{\circ} 10^{\prime} 31.5^{\prime \prime} \mathrm{E}\right)$ close to Lake 200 Sempach, Switzerland. The area surrounding the tall-tower station is predominantly used

201 for agriculture. The two larger towns closest to the tall tower are Lucerne $(\approx 20 \mathrm{~km})$ and $202 \mathrm{Zug}(\approx 30 \mathrm{~km})$. The tall tower is the taller of two former national radio broadcast towers 203 and is protected as a national monument, and is no longer used for telecommunication.

204 Although greenhouse gas and meteorological measurements were made at five different 205 heights, we have only used measurements from the top of the tower at an elevation of $2061009 \mathrm{~m}$ a.s.1. (212 $\mathrm{m}$ above ground level), similar to the elevation of measurements at 207 Früebüel. Air temperatures recorded at this elevation ranged from $-9.9^{\circ} \mathrm{C}$ to $29.1^{\circ} \mathrm{C}$ in 208 the year 2013 , resulting in an annual average of $7.3^{\circ} \mathrm{C}$.

2102.2 Instrumentation

211 Mixing ratios of $\mathrm{CO}_{2}$ and $\mathrm{CH}_{4}$ at the mountain-top station (Früebüel) were measured with 212 a cavity ring-down spectrometer (Picarro G2301, Picarro Inc., Santa Clara, California, 213 USA), while the tall-tower station (Beromünster) was equipped with a Picarro G2401 214 analyzer that also measured CO mixing ratios. Both instruments were operated at a 215 standard cavity pressure of $186.7 \mathrm{hPa}$ and a cavity temperature of $45^{\circ} \mathrm{C}$. All times 216 reported here are given in UTC, which differs by one hour from local time (CET-1 h).

217 Früebuiel: The air inlet was covered by an inlet filter (F-15-050, Solberg International, 218 Ltd., Itasca, IL, USA). Ambient air was drawn through an insulated and heated Synflex 2191300 hose to the analyzer, which was placed within an air-conditioned $\left(20-28^{\circ} \mathrm{C}\right)$ 220 container. Automatic recalibration of the system was performed daily using three 221 reference gases (high: $\mathrm{CO}_{2} / \mathrm{CH}_{4}$ mixing ratios 475.3/2.398 ppm; low: 383.5/1.895 ppm; 222 working: 405.2/2.056 ppm). Calibration gases were traced to the WMO primary 223 standards WMO-X2007 for $\mathrm{CO}_{2}$ and WMO-X2004 for $\mathrm{CH}_{4}$. The accuracy of the 224 greenhouse gas measurements was estimated at $\leq 0.07 \mathrm{ppm}$ and $\leq 0.0005 \mathrm{ppm}$ for $\mathrm{CO}_{2}$ 225 and $\mathrm{CH}_{4}$, respectively (Oney et al. 2015). Details about the meteorological sensors are 226 given by Zeeman et al. (2010). 
227 Beromünster: At the Beromünster tall tower, air was drawn at a flow rate of $14 \mathrm{~L} \mathrm{~min}^{-1}$ 228 from the highest level $(212 \mathrm{~m})$ to the analyzer through a $220 \mathrm{~m}$ long inlet tube. The 229 analyzer was placed within the old radio transmitter building at the base of the tower, and 230 automatic calibration was done once a week (high: 472.66/2.4247 ppm; low: $231382.11 / 1.9089 \mathrm{ppm}$ ) similarly to Früebüel. In addition, every $6 \mathrm{~h}$ measurements were 232 compared with a working gas standard (392.24/2.1312 ppm), see Berhanu et al. (2016).

233 Meteorological measurements at the highest level of the tall tower were provided by an 234 integrated weather station (MetPak $^{\mathrm{TM}}$ II Remote, Gill Instruments Ltd, Lymington, 235 Hampshire, UK). The weather station included sensors to measure wind direction and 236 speed, air temperature, relative humidity, and barometric pressure. All measurements 237 were performed at 1-s resolution and processed to 2-h averages for data analysis.

2392.3 Data Analysis

240 Comparisons between the two sites initially used 1-min average mixing ratios aggregated 241 to 2-h intervals if at least $20 \%$ of the 1-min averages represented concurrent 242 measurements at both sites. For each 2-h interval the following two statistical parameters 243 were computed: (1) the average greenhouse gas mixing ratios; and (2) the quantile of the $244 \mathrm{CO}_{2}$ and $\mathrm{CH}_{4}$ frequency distribution within each 2-h interval based on 1-min data, which 245 separates the lowest $5 \%$ from the upper $95 \%$ of the observed mixing ratios (referred to 246 as the $5^{\text {th }}$ percentile). Similar to the arithmetic mean or the median $\left(=50^{\text {th }}\right.$ percentile $)$, the

$2475^{\text {th }}$ percentile acts as a low-pass filter. This was necessary since the frequency distribution 248 of $\mathrm{CH}_{4}$ mixing ratios is positively skewed towards higher mixing ratios at the mountain249 top station. In contrast, the lower tail of the frequency distribution is much less influenced 250 by outliers, thus suggesting that the $5^{\text {th }}$ percentile is more likely to represent air parcels 251 unaffected by local sources than the arithmetic mean. One drawback of the $5^{\text {th }}$ percentile, 252 however, is its high sensitivity to local sinks (for example the biospheric sink for $\mathrm{CO}_{2}$ ). 253 Two-hourly averages and $5^{\text {th }}$ percentile values were used for further analysis of the 254 atmospheric greenhouse gas mixing ratios at the two stations.

255 To identify a filter criterion for the mountain-top station that eliminates unwanted local 256 influences that do not relate to regional-scale greenhouse gas fluxes, we evaluated 
257 differences between mountain-top and tall-tower mixing ratios using these aggregated 258 data. We calculated binned average differences according to wind speed, wind direction 259 and atmospheric stability at the mountain-top site (see Supplementary Material, Section 260 S2).

261 To determine the level of agreement between wind-direction measurements at the two 262 sites, we used a kernel distribution in a polar coordinate system. The kernel density 263 estimation of wind direction was calculated using the procedure described by Botev et al. 264 (2010). As differences in $\mathrm{CH}_{4}$ mixing ratios between the mountain-top and the tall-tower 265 sites may be due to local $\mathrm{CH}_{4}$ sources at the mountain-top site, we investigated between266 site differences in $\mathrm{CH}_{4}$ mixing ratios and their dependence on wind direction observed at 267 the mountain-top site. To this end, we grouped the differences between the corresponding 268 2-h tall-tower and mountain-top mixing ratios into 18 wind sectors (each spanning $20^{\circ}$ ).

269 Then, the average differences in $\mathrm{CH}_{4}$ mixing ratios between the sites were calculated for 270 daytime (0800-1600 UTC) and nighttime (2000-0400 UTC), summer (April to October) 271 and winter (November to March) and for each wind sector. More detailed information on 272 the aggregation of these classes is presented in the Supplementary Material (Section S3, 273 Figs. S2 and S4). For $\mathrm{CO}_{2}$, the same procedure was repeated using a slightly modified 274 temporal (morning: 0800-1200 UTC, afternoon: 1200-1600 UTC, evening: 2000-2400 275 UTC and night: 0000-0400 UTC) and seasonal classification (spring: April to June, 276 summer/autumn: July to October, winter: November to March) to account for the 277 differences in sources and sinks of $\mathrm{CO}_{2}$ in comparison with $\mathrm{CH}_{4}$.

278 In order to determine the general agreement between the two sites, we used the $5^{\text {th }}$ 279 percentile time series and the time series after removing periods with unfavourable flow 280 conditions for $\mathrm{CO}_{2}$ and $\mathrm{CH}_{4}$ and calculated the bias and Pearson's correlation coefficients 281 between the tall-tower and the mountain-top stations. The bias after filtering was 282 evaluated for different months and times of day, whereas the correlation coefficient was 283 calculated between the filtered time series of $\mathrm{CO}_{2}$ and $\mathrm{CH}_{4}$ mixing ratios within time 284 periods of \pm 7 days centred at each 2-h value. 


\section{Results}

3.1 Wind Directions at the Tall-tower and the Mountain-top Site

290 Wind directions at the mountain-top site were similar to those at the tall-tower site (Fig.

$2912 \mathrm{a}, \mathrm{b})$, but with a few noteworthy differences. Wind directions at the tall-tower site were

292 dominated by the typical south-westerly and north-easterly directions found over the

293 Swiss Plateau due to the channelling of flow between the Alps and the Jura mountains

294 (Wanner and Furger 1990). In contrast, the flow at the mountain-top site was generally

295 much weaker and arriving from more variable wind directions. Strongest wind at the 296 mountain-top site was observed from the south-easterly sector (around $150^{\circ}$ ), most 297 probably corresponding to foehn wind.
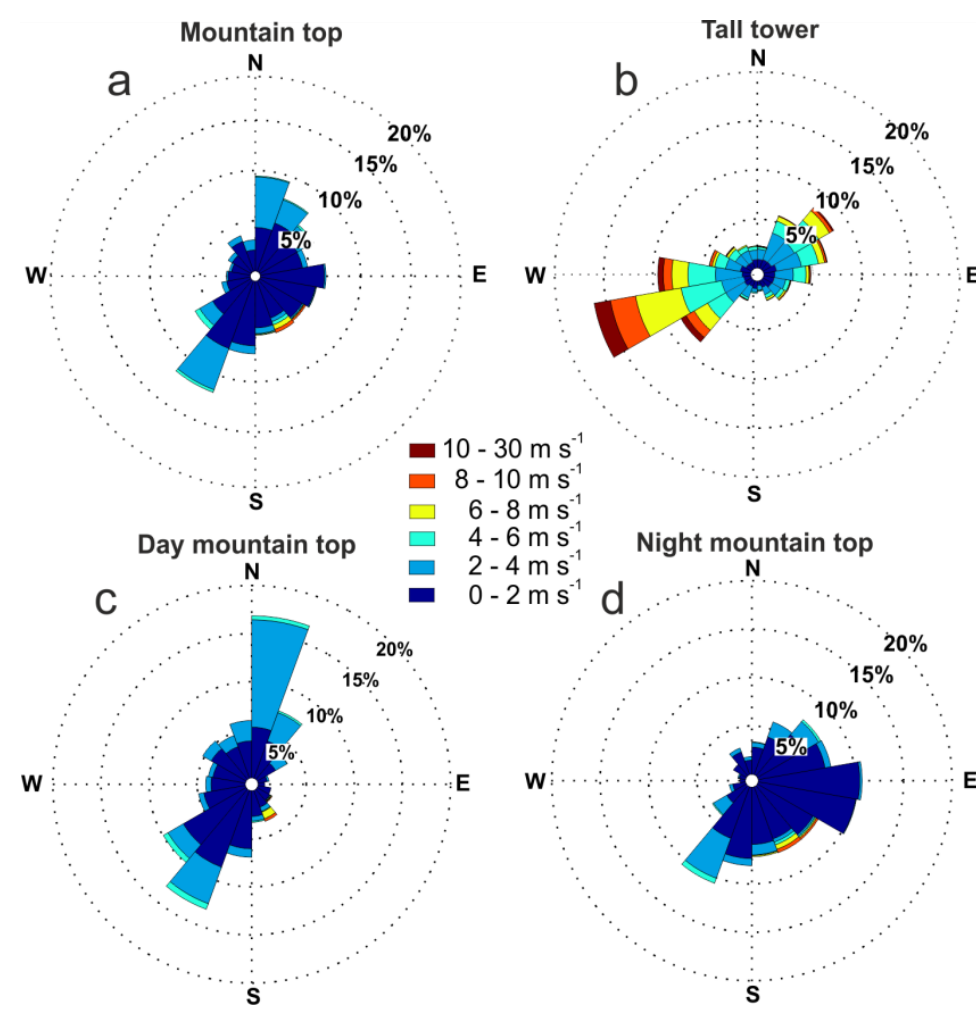

Night mountain top

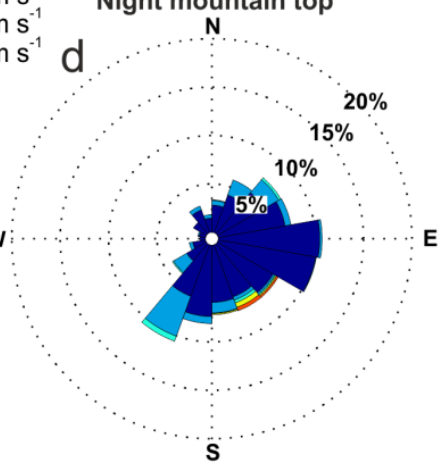

Fig. 2 Wind-rose plots for the measurement stations Früebüel (mountain top, a) and Beromünster (tall tower, b) during the year 2013 additionally separated for daytime (0800-1600 UTC, c) and nighttime (0000-0400 UTC, d) at the mountain-top station

303 To emphasize the influence of diurnal variations due to thermally-forced slope flow, Fig.

$3042 \mathrm{c}$, d show wind roses at the mountain-top site separately for daytime and nighttime. 
305 While flow from northerly directions was most frequent during daytime, nighttime flow 306 was predominantly from southerly or easterly directions. Flow from easterly and westerly 307 directions was generally weak, more frequently arriving from the east at night and from 308 the west during the day.

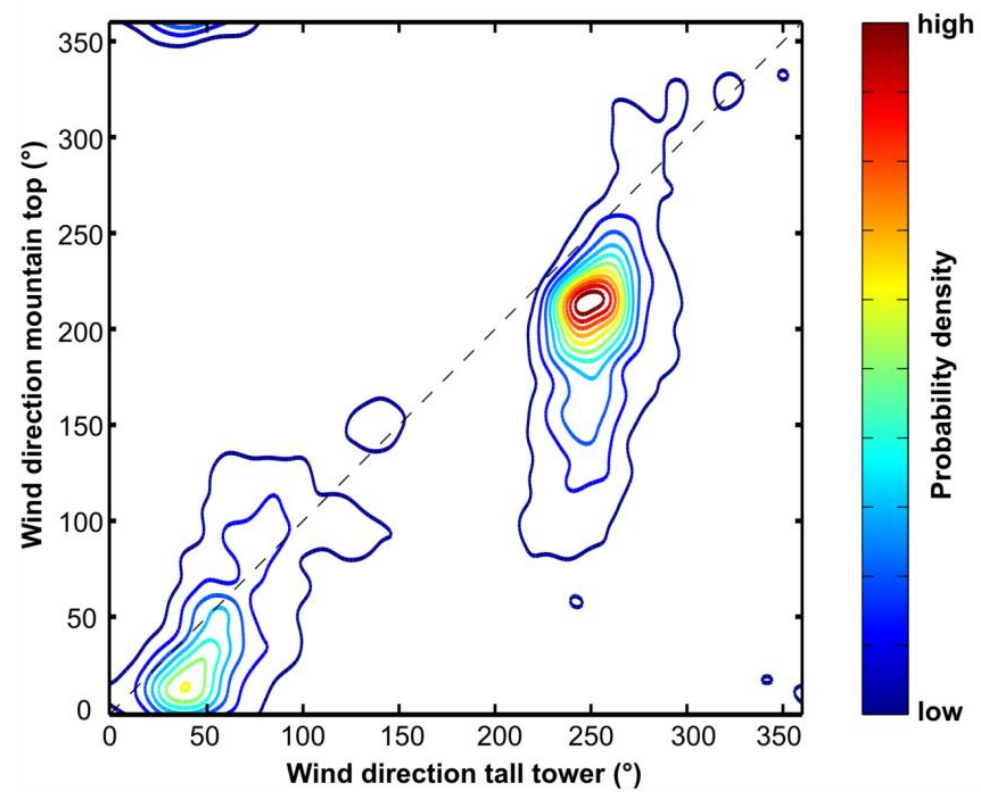

310 Fig. 3 Probability density distribution of wind directions at the Beromünster tall-tower station (horizontal 311 axis) versus the Früebüel mountain-top station (vertical axis) based on a bivariate kernel density estimation.

312 Reddish colours denote a high probability density, while bluish colours depict lower probability densities

314 The kernel density plot of the bivariate probability distribution between wind directions

315 (Fig. 3) showed that flows from the north-easterly sector at the tall-tower site were 316 accompanied by flows from a similar direction also at the mountain-top site. Larger

317 directional spread was found at the mountain-top site, whereas the tall-tower site 318 experienced rather well defined south-westerly flow $\left(220^{\circ}-270^{\circ}\right)$. Under these 319 conditions, the wind directions at Früebüel varied over a wider range of angles, but the 320 peak of the joint probability distribution showed a relatively small directional bias $321\left(\approx 20^{\circ}-30^{\circ}\right)$, likely reflecting the influence of the surface drag at the mountain top 322 compared to the tower measurements that are more representative of mid-boundary layer 323 conditions. 
326 Methane: Despite notable differences in wind direction and wind speed between the two 327 sites (Figs. 2 and 3), $\mathrm{CH}_{4}$ mixing ratios followed a similar seasonal course (Fig. 4a), with 328 mixing ratios varying roughly between $1.8 \mathrm{ppm}$ and $2.2 \mathrm{ppm}$. Peak $\mathrm{CH}_{4}$ mixing ratios 329 observed at the mountain-top site, however, deviated by up to $0.2 \mathrm{ppm}$ from mixing ratios 330 observed at the tall-tower site. The positive outliers were most likely influenced by local $331 \mathrm{CH}_{4}$ sources at the mountain-top site.
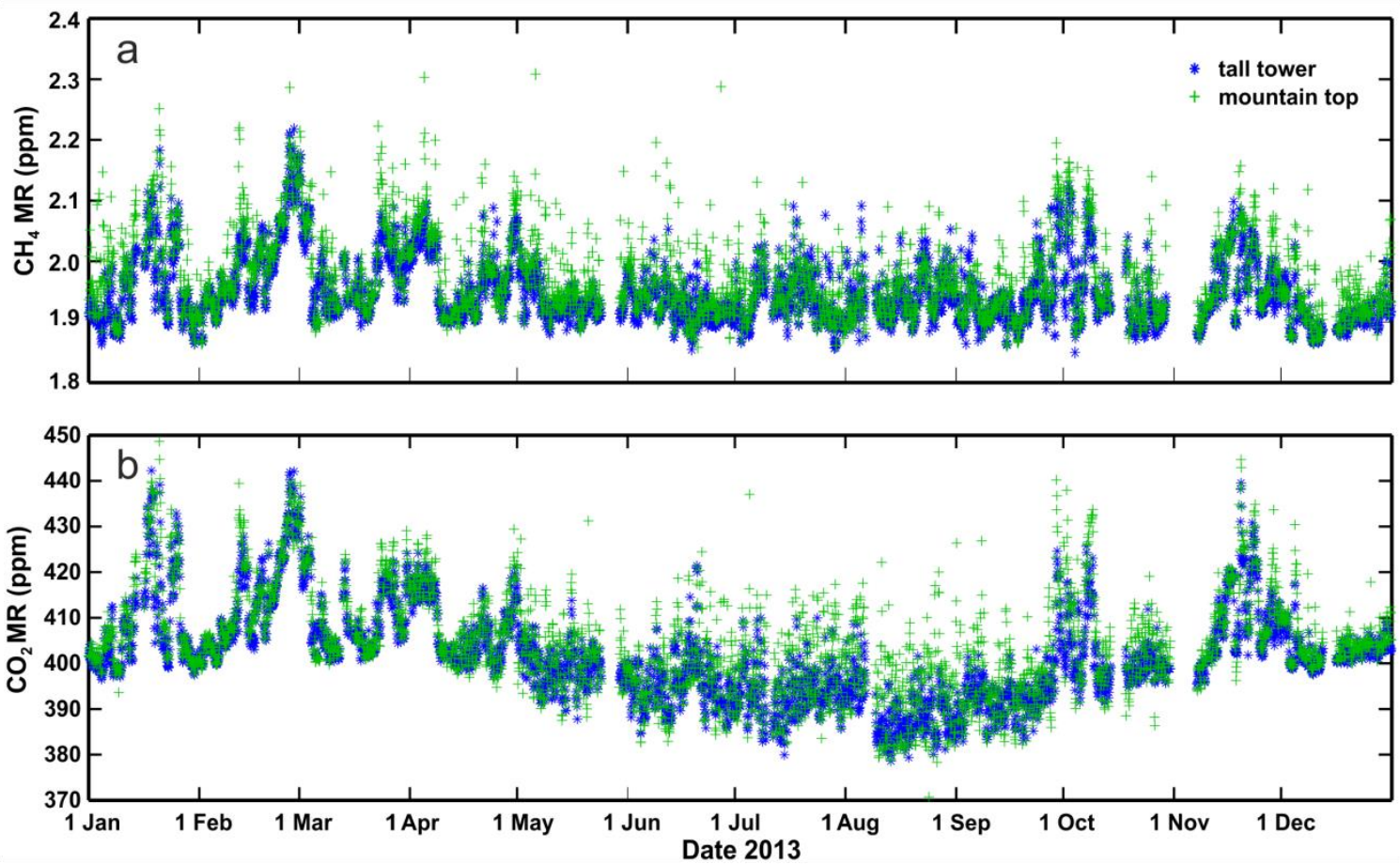

333 Fig. 4 Time series of 2-h averages of $\mathrm{CH}_{4}(\mathbf{a})$, and $\mathrm{CO}_{2}$ (b) mixing ratios measured at the Beromünster tall334 tower station (blue symbols) compared to those measured at the Früebüel mountain-top station (green symbols) from January to December 2013

337 For average $\mathrm{CH}_{4}$ mixing ratios these differences between the two stations remained 338 generally below $0.02 \mathrm{ppm}$ for any wind direction, except for southerly flow from the 339 direction of the ETH research station when average mixing ratios at the mountain-top site 340 were considerably higher (up to 0.065 ppm, Fig. S1 in Supplementary Material). This 341 pattern indicates that the major source for methane at this site is the farmstead of the ETH 342 research station. 

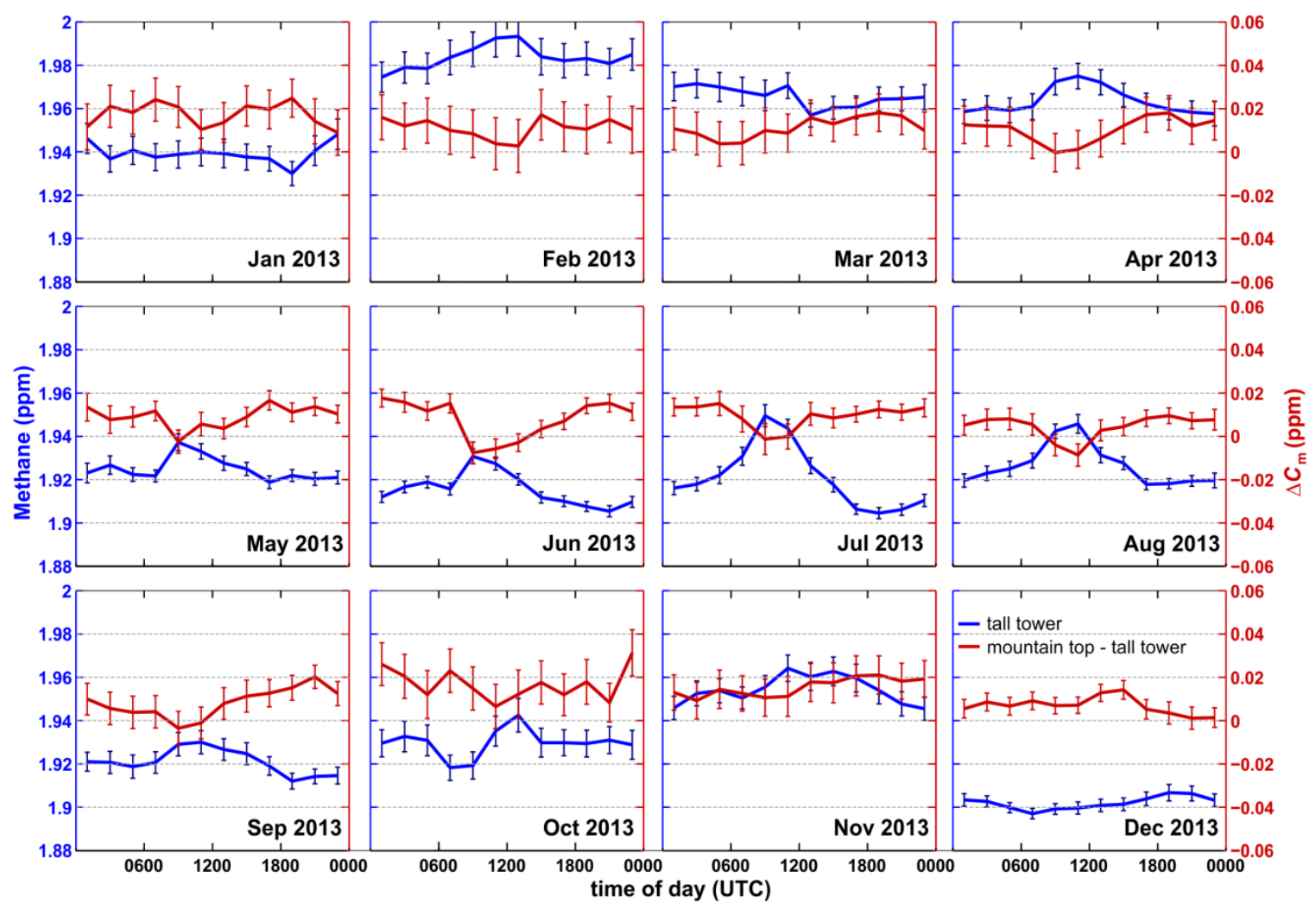

344 Fig. 5 Monthly average diurnal cycles derived from the $5^{\text {th }}$ percentiles of the 2-h frequency distribution of $345 \mathrm{CH}_{4}$ mixing ratios observed at the Beromünster tall-tower station (blue colour) and the difference in $\mathrm{CH}_{4}$ 346 mixing ratios between the mountain-top and the tall-tower stations $\left(\Delta C_{\mathrm{m}}\right.$, red colour) including the corresponding 95\% confidence interval (vertical bars) from January to December 2013

349 The influence of local sources was investigated by analyzing monthly aggregated diurnal 350 patterns of the $5^{\text {th }}$ percentiles of the $\mathrm{CH}_{4}$ mixing ratios at 2-h resolution. Such $\mathrm{CH}_{4}$ 351 mixing ratios only showed weak diurnal patterns at the mountain top, whereas an increase 352 of up to $0.025 \mathrm{ppm}$ was seen in the late morning or around midday at the tall-tower 353 station, especially during the summer months (Fig. 5). Except for the late 354 morning/midday minima when methane mixing ratios at the mountain-top station were 355 lower than at the tall-tower station, monthly averages of $\mathrm{CH}_{4}$ mixing ratios were 356 moderately but significantly higher at the mountain-top site (between $0.005 \mathrm{ppm}$ in 357 August and $0.020 \mathrm{ppm}$ in January) than at the tall-tower site (Fig. 5, red line). A generally 358 weak bimodal seasonal pattern of methane mixing ratios was observed. At both sites, 359 mixing ratios were low during winter (December and January), reached their first 
360 maximum during February, then declined slowly during the summer and exhibited a 361 second maximum in November.

362 Carbon dioxide: During winter, $\mathrm{CO}_{2}$ mixing ratios at the mountain-top and tall-tower 363 stations almost followed the same temporal course, mostly fluctuating between $400 \mathrm{ppm}$ 364 (daytime) and $440 \mathrm{ppm}$ (nighttime; Fig. 4b). In summer, however, the average $\mathrm{CO}_{2}$ 365 mixing ratios at the mountain top station were lower and varied between $380 \mathrm{ppm}$ and $366420 \mathrm{ppm}$. In general, $\mathrm{CO}_{2}$ mixing ratios in summer were lower than in winter.
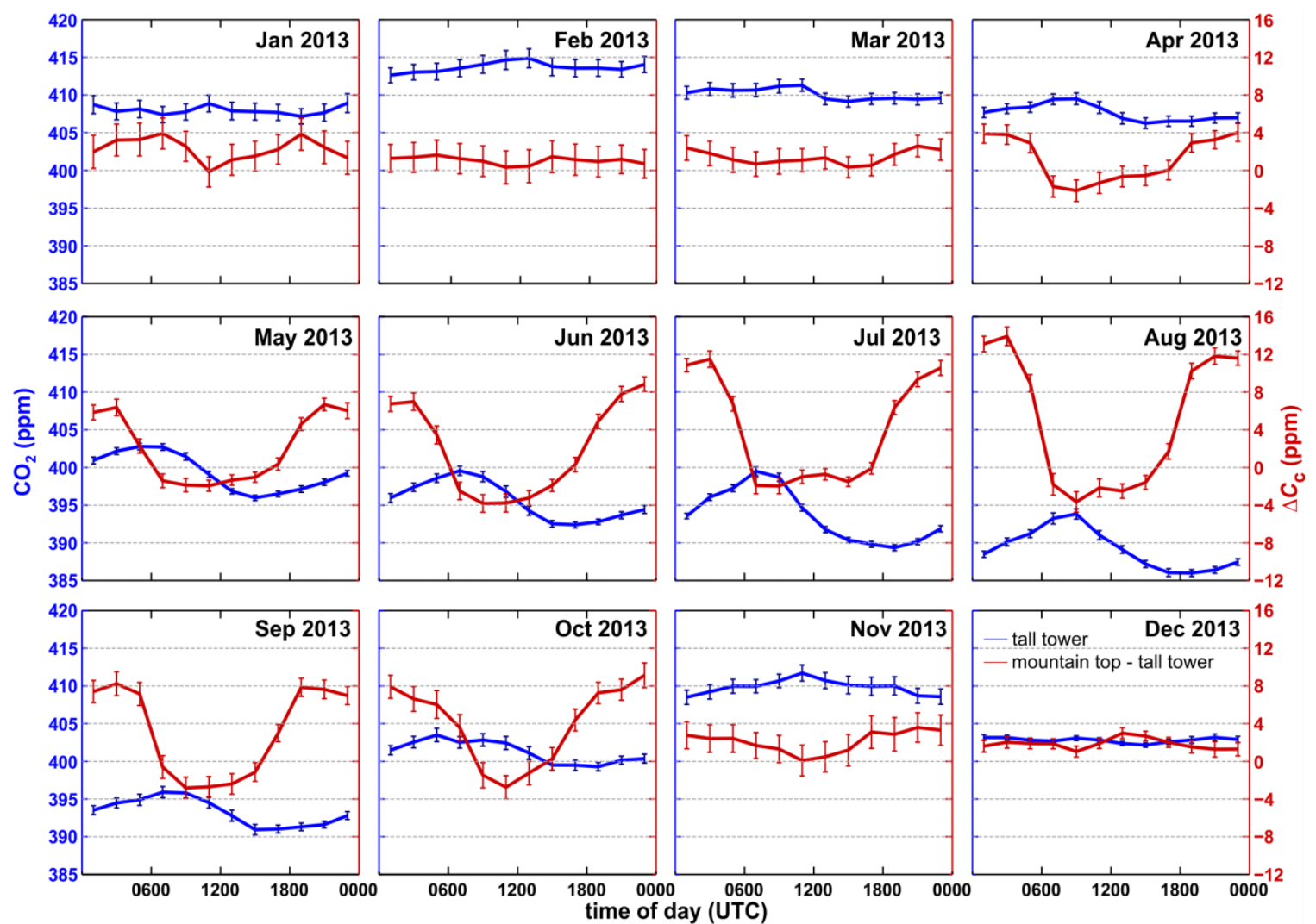

Fig. 6 Monthly average diurnal cycles of the 2-h frequency distribution of $\mathrm{CO}_{2}$ mixing ratios observed at the Beromünster tall-tower station (blue colour) and the difference in $\mathrm{CO}_{2}$ mixing ratios between the talltower and the mountain-top stations $\left(\Delta C_{\mathrm{c}}\right.$, red colour) including the corresponding $95 \%$ confidence interval (vertical bars) from January to December 2013

373 To investigate the difference in summertime $\mathrm{CO}_{2}$ mixing ratios between the two sites, 374 average diurnal cycles of $\mathrm{CO}_{2}$ for each month and both stations were calculated in an 375 analogous manner to $\mathrm{CH}_{4}$, but using averages instead of $5^{\text {th }}$ percentiles (since the $5^{\text {th }}$ 
376 percentile approach did not work satisfactorily for $\mathrm{CO}_{2}$ ) (Fig. 6). During wintertime, only 377 a weak diurnal cycle of $\mathrm{CO}_{2}$ mixing ratios could be seen at the tall-tower station, showing 378 a slight increase of up to $4 \mathrm{ppm}$ during midday. This increase in midday $\mathrm{CO}_{2}$ mixing 379 ratios was not observed at the mountain-top station and thus the bias between the 380 mountain-top and the tall-tower stations (red line in Fig. 6) usually decreased around this 381 time of day. $\mathrm{CO}_{2}$ mixing ratios always remained close to $410 \mathrm{ppm}$ (except during 382 December when $\mathrm{CO}_{2}$ mixing ratios approached $400 \mathrm{ppm}$ ). In summer, $\mathrm{CO}_{2}$ mixing ratios 383 at the mountain-top site showed a typical diurnal cycle with lowest values during daytime 384 and a maximum at night. Summertime $\mathrm{CO}_{2}$ mixing ratios at the tall-tower site had their 385 maximum in the morning and reached lowest values in the afternoon. Thus, the bias in $386 \mathrm{CO}_{2}$ mixing ratios was usually negative during the day and positive at nighttime.
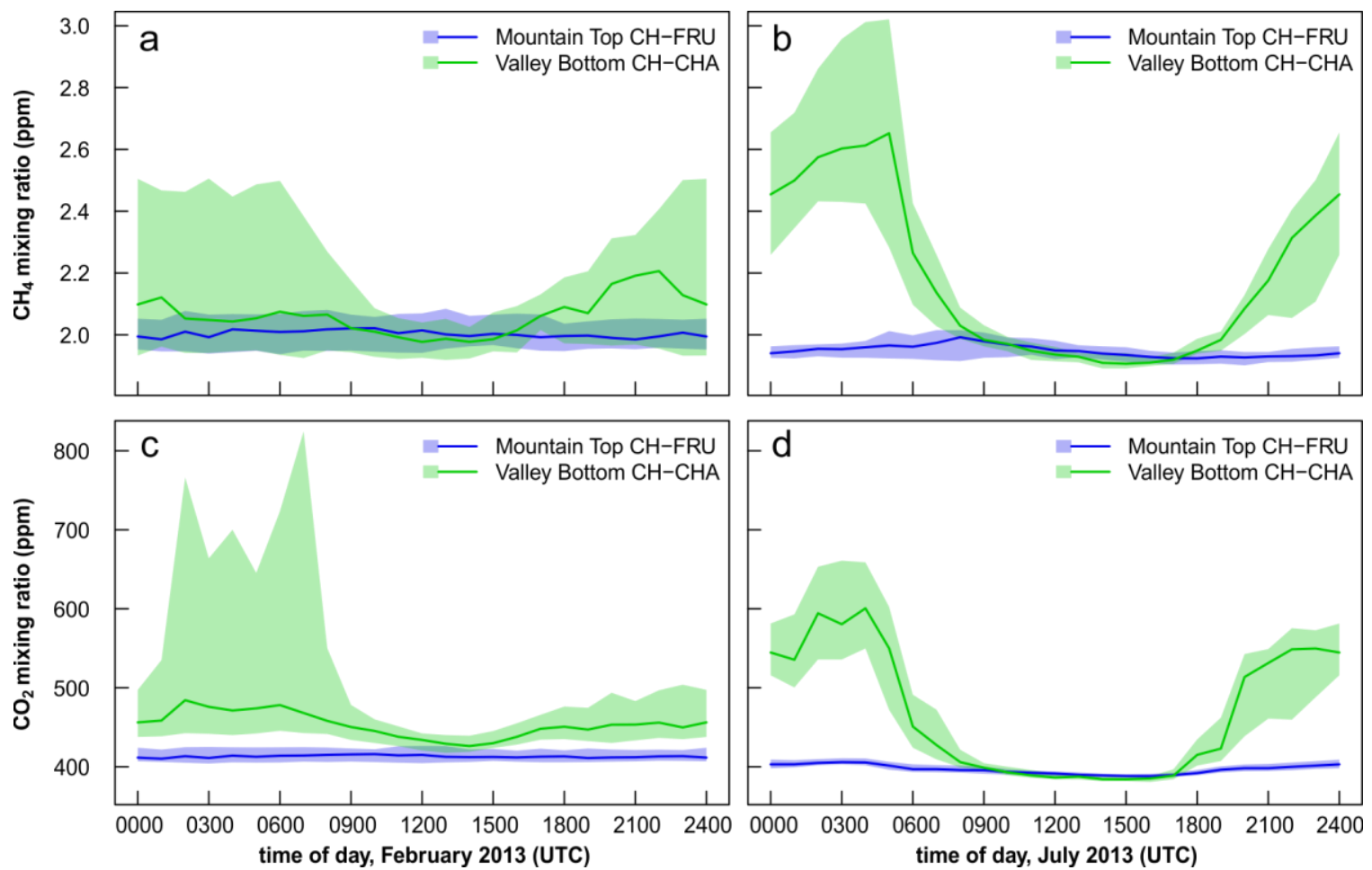

Fig. 7 Diurnal cycles of median $\mathrm{CH}_{4}(\mathbf{a}, \mathbf{b})$ and $\mathrm{CO}_{2}(\mathbf{c}, \mathbf{d})$ mixing ratios at the mountain-top station (Früebüel CH-FRU, blue colour) and a nearby valley-bottom station at $393 \mathrm{~m}$ a.s.l. (Chamau CH-CHA $47^{\circ} 12^{\prime} 37^{\prime \prime} \mathrm{N}, 8^{\circ} 24^{\prime} 38^{\prime \prime} \mathrm{E}$, green colour; Merbold et al. 2014) for a representative month in the winter (February 2013, a, c) and summer (July 2013, b, d). The green and blue shaded areas indicate the interquartile range for the valley bottom and mountain-top station, respectively 
394 Near-surface $\mathrm{CH}_{4}$ mixing ratios at the mountain-top site showed a less distinct diurnal

395 cycle than at a nearby (ca. $15 \mathrm{~km}$ distance) valley-bottom site (Chamau, cf. Fig.7), where

396 nighttime $\mathrm{CH}_{4}$ mixing ratios increased up to $2.4 \mathrm{ppm}$ and $2.2 \mathrm{ppm}$ in July and February,

397 respectively. These valley-bottom data were collected and published by Merbold et al.

398 (2014) and are only shown for comparison. A similar difference between mountain-top 399 and valley-bottom sites is seen in $\mathrm{CO}_{2}$ mixing ratios, with a very weak nighttime increase 400 of approximately 20 ppm at the mountain-top site in July 2013 as compared to the 200-

401 ppm increase observed at the valley-bottom site.

403 3.3. Filtering $\mathrm{CH}_{4}$ and $\mathrm{CO}_{2}$ and Mixing Ratio Differences to Minimize Local Influences

404 The percentile filtering approach revealed to be highly capable of removing a relevant 405 share of mixing ratios influenced by local sources, but is not based on physical 406 considerations, since it only uses a statistical filtering criterion. Hence, we also applied a 407 second filtering approach that employs meteorological information. With this second 408 approach, wind speeds and wind directions could be identified that led to large 409 differences between mountain-top and tall-tower measurements. These were then 410 discarded. From the retained subset of measurements, the signal with minimal influence 411 of local conditions was extracted as a function of time of day and season. An analysis of 412 variance approach was used to determine the aggregation levels for wind speed, wind 413 direction, time of day, and seasonality. The aggregation levels differed slightly for $\mathrm{CH}_{4}$ 414 and $\mathrm{CO}_{2}$ mixing ratios. Details are given in Supplementary Material, Sections S3.1 and 415 S3.2. For simplicity, we termed this meteorological filtering the "WDS filter" (W for 416 wind speed and direction, D for time of day, and S for seasonality).

417 The differences of $\mathrm{CH}_{4}$ mixing ratios between the mountain-top and the tall-tower sites $418\left(\Delta C_{\mathrm{m}}\right)$ were best explained by the four factors: wind direction (three classes), wind speed 419 (five classes), time of day (separated into daytime 0800-1600 UTC and nighttime 00004200400 UTC), and seasonality (two classes: summer, April to October; and winter, 421 November to March). For $\mathrm{CO}_{2}$, the between-site difference of mixing ratios $\left(\Delta C_{\mathrm{c}}\right)$ 422 depended on the same four factors but required a higher degree of detail, with four 423 classes for time of day (morning: 0800-1200 UTC, afternoon: 1200-1600, evening: 
424 2000-2400 UTC, and night: 0000-0400 UTC) and three classes for season (spring: April 425 to June, summer/autumn: July to October, and winter: November to March). Transition 426 periods between night and morning (0400-0800 UTC) and between afternoon and 427 evening (1600-2000 UTC) were excluded from this analysis since during these time 428 periods conditions are changing rapidly and may result in mixing ratios that are 429 representative of neither daytime nor of nighttime conditions. This classification was 430 coarse enough to be meaningful but still detailed enough to represent the pronounced 431 diurnal cycle of the $\mathrm{CO}_{2}$ mixing ratios (Fig. 6).

432 Before applying such a filter, a clear dependence of $\Delta C_{\mathrm{m}}$ and $\Delta C_{\mathrm{c}}$ mixing ratio 433 differences on all four factors was obvious (Figs. 8 and 9). Wind direction had a 434 comparatively larger influence on $\Delta C_{\mathrm{m}}$ (Fig. 8) than $\Delta C_{\mathrm{c}}$ (Fig. 9).

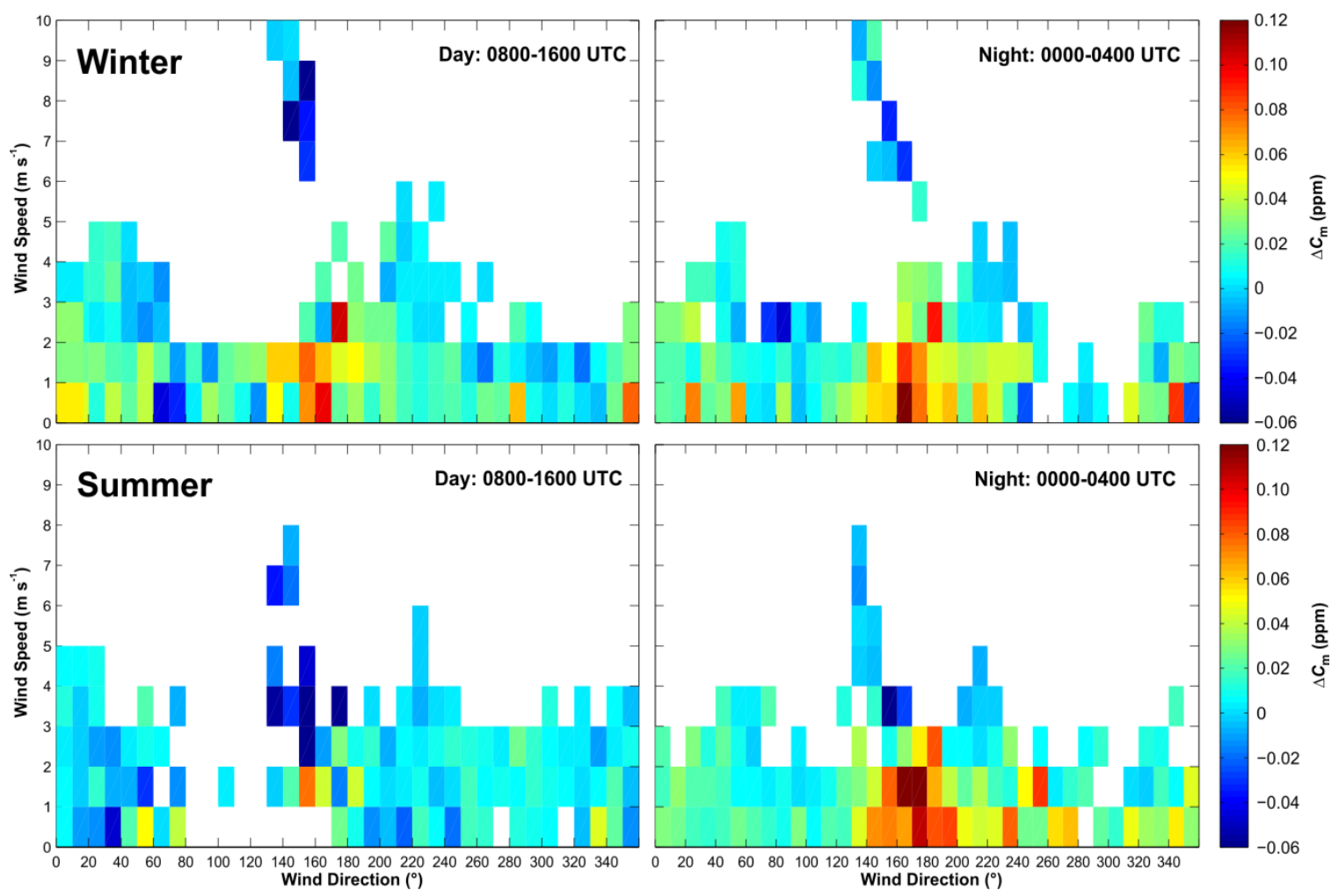

Fig. 8 Average differences of daytime (0800-1600 UTC, left) and nighttime (0000-0400 UTC, right) $\mathrm{CH}_{4}$ mixing ratios between mountain-top and tall-tower station $\left(\Delta C_{\mathrm{m}}\right)$ during the winter season (NovemberMarch, top) and the summer season (April-October, bottom), binned for different wind direction and wind 439 speed classes at the mountain top 
441 Under strong (> $\left.3 \mathrm{~m} \mathrm{~s}^{-1}\right)$ south-easterly flow (130 ${ }^{\circ}$ to $\left.170^{\circ}\right), \mathrm{CH}_{4}$ mixing ratios tended to 442 be up to $0.06 \mathrm{ppm}$ lower at the mountain-top site compared to the tall-tower site, 443 especially during daytime (Fig. 8). In contrast, $\mathrm{CH}_{4}$ mixing ratios were up to $0.07 \mathrm{ppm}$ 444 higher at the mountain-top site compared to the tall-tower site with wind speeds $<3 \mathrm{~m} \mathrm{~s}^{-1}$ 445 and wind directions from $120^{\circ}$ to $200^{\circ}$ corresponding to the sectors influenced by the 446 ETH farmstead (Fig. S1). Negative $\Delta C_{\mathrm{m}}$ mixing ratio differences were also observed 447 during easterly flow $\left(60^{\circ}-120^{\circ}\right)$ with wind speeds $>2 \mathrm{~m} \mathrm{~s}^{-1}$. Especially in summer, 448 positive deviations of the mountain-top from the tall-tower measurements tended to be 449 higher during the night than during the day.

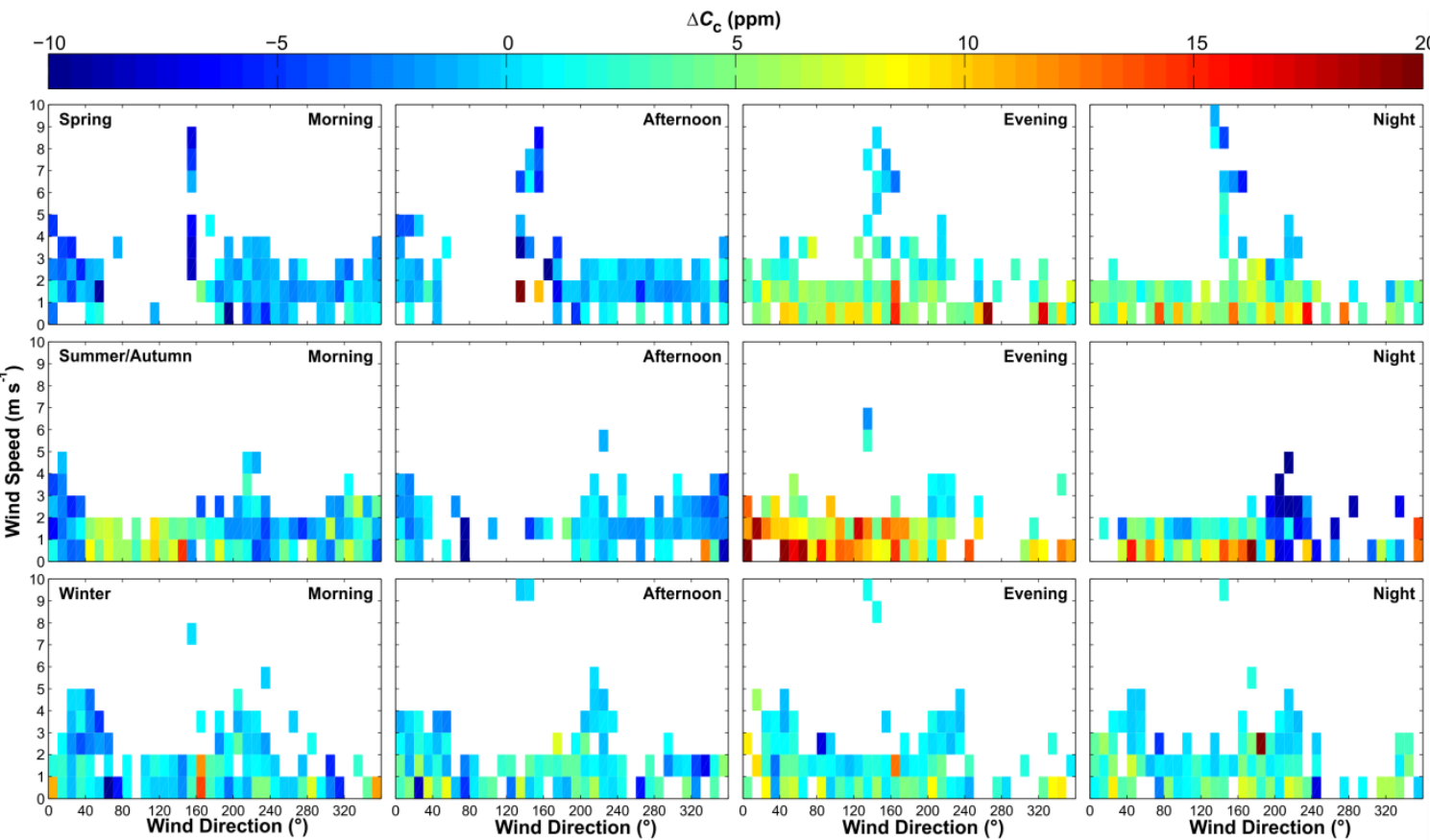

451 Fig. 9 Average differences of morning (0800-1200 UTC, left), afternoon (1200-1600 UTC), evening 452 (2000-2400 UTC), and night (0000-0400 UTC) $\mathrm{CO}_{2}$ mixing ratios between mountain-top and tall-tower 453 station $\left(\Delta C_{\mathrm{c}}\right)$ during spring (April-June, top), summer/autumn (July-October, centre) and the winter season 454 (November-March, bottom) binned for different wind direction and wind speed classes at the mountain top

456 The weak wind direction dependency of $\Delta C_{\mathrm{c}}$ (Fig. 9) compared to $\Delta C_{\mathrm{m}}$ (Fig. 8) is not 457 surprising because the main local source and sink for $\mathrm{CO}_{2}$ at the mountain top is the 458 vegetation which extends around the measurement station in all directions. During spring, 459 daytime $\mathrm{CO}_{2}$ mixing ratios (morning, afternoon) at the mountain-top station were 
460 generally lower than at the tall-tower station, irrespective of wind direction. Contrastingly,

$461 \mathrm{CO}_{2}$ mixing ratios measured during evening and night were increased at the mountain-top

462 station as compared to the tall-tower station. Similar conditions were found in

463 summer/autumn except with easterly wind directions in the morning $\left(\Delta C_{\mathrm{c}}>0 \mathrm{ppm}\right)$ and

464 with south-westerly wind directions during the night $\left(\Delta C_{\mathrm{c}}<0 \mathrm{ppm}\right)$. In winter, $\Delta C_{\mathrm{c}}$ was

465 generally smaller than in summer, and wind directions $90^{\circ}-160^{\circ}$ and $190^{\circ}-260^{\circ}$ tended

466 to show the smallest differences between the mountain-top and the tall-tower

467 measurements (Fig. 9).

468

469 3.4 Comparison of Greenhouse Gas Mixing Ratios

470 All wind directions with strong local influence on $\mathrm{CH}_{4}$ or $\mathrm{CO}_{2}$ mixing ratios were filtered

471 out based on the analysis of variance results shown in Supplementary Material (Tables S2

472 and S3). $\mathrm{CH}_{4}$ mixing ratios were maintained if the following conditions were met: (1)

473 summer daytime wind directions in the range $0^{\circ}-50^{\circ}$ or $190^{\circ}-360^{\circ}$, (2) summer

474 nighttime wind directions in the range $10^{\circ}-120^{\circ}$ or $200^{\circ}-360^{\circ}$ in combination with

475 wind speeds $>2 \mathrm{~m} \mathrm{~s}^{-1}$, (3) winter daytime wind directions in the range $0^{\circ}-70^{\circ}$

476 combined with wind speeds $>2 \mathrm{~m} \mathrm{~s}^{-1}$, (4) winter daytime wind directions in the range

$477220^{\circ}-360^{\circ}$ combined with wind speeds $>1 \mathrm{~m} \mathrm{~s}^{-1}$, (5) winter nighttime wind speeds in

478 the range $1-2 \mathrm{~m} \mathrm{~s}^{-1}$ and wind directions in the range $40^{\circ}-130^{\circ}$, and (6) winter nighttime

479 wind directions in the range $200^{\circ}-260^{\circ}$ and wind speeds $>2 \mathrm{~m} \mathrm{~s}^{-1}$. The remaining $\mathrm{CH}_{4}$

480 mixing ratios were used for further analysis.

$481 \mathrm{CO}_{2}$ mixing ratios at the mountain-top station during spring or autumn were generally

482 either higher or lower than at the tall-tower station, thus filtering of $\mathrm{CO}_{2}$ mixing ratios

483 was problematic: In winter only $\mathrm{CO}_{2}$ mixing ratios could be retained when wind direction

484 was $90^{\circ}-160^{\circ}$ or $190^{\circ}-260^{\circ}$ in combination with wind speeds $>1 \mathrm{~m} \mathrm{~s}^{-1}$ irrespective of

485 time of day. In summer, all $\mathrm{CO}_{2}$ mixing ratios at the mountain-top station were strongly

486 affected by $\mathrm{CO}_{2}$ uptake (photosynthesis) by vegetation during daytime and $\mathrm{CO}_{2}$ release

487 (respiration) during the night. With this data screening, $35 \%$ of the $\mathrm{CH}_{4}$ mixing ratios

488 and $9 \%$ of the $\mathrm{CO}_{2}$ mixing ratios measured at the mountain-top station could be retained

489 (Fig. 10 a, c). 
491 Table 1 Average differences between the $\mathrm{CH}_{4}\left(\Delta C_{\mathrm{m}}\right)$ and $\mathrm{CO}_{2}\left(\Delta C_{\mathrm{c}}\right)$ mixing ratios at the 492 mountain-top and the tall-tower station after the application of the WDS filter

\begin{tabular}{|c|c|c|c|c|}
\hline & \multicolumn{4}{|c|}{ average $\Delta C_{\mathrm{m}}$ mixing ratio difference \pm standard deviation $\Delta C_{\mathrm{m}}(\mathrm{ppm})$} \\
\hline & Night & Morning & Afternoon & Evening \\
\hline January & $-0.0018 \pm 0.0026$ & $0.0392 \pm 0.0041$ & $0.0252 \pm 0.0025$ & $0.0030 \pm 0.0017$ \\
\hline February & $0.0041 \pm 0.0009$ & $0.0008 \pm 0.0024$ & $0.0038 \pm 0.0023$ & $0.0121 \pm 0.0016$ \\
\hline March & $0.0077 \pm 0.0015$ & $0.0030 \pm 0.0033$ & $0.0135 \pm 0.0018$ & $0.0144 \pm 0.0019$ \\
\hline April & $0.0074 \pm 0.0013$ & $-0.0050 \pm 0.0018$ & $0.0084 \pm 0.0011$ & $0.0167 \pm 0.0016$ \\
\hline May & $0.0083 \pm 0.0013$ & $0.0082 \pm 0.0016$ & $0.0157 \pm 0.0013$ & $0.0296 \pm 0.0028$ \\
\hline June & $0.0319 \pm 0.0030$ & $-0.0019 \pm 0.0018$ & $0.0043 \pm 0.0013$ & $0.0348 \pm 0.0035$ \\
\hline July & $0.0091 \pm 0.0018$ & $-0.0052 \pm 0.0026$ & $0.0113 \pm 0.0017$ & $0.0071 \pm 0.0010$ \\
\hline August & $-0.0018 \pm 0.0010$ & $-0.0149 \pm 0.0022$ & $0.0033 \pm 0.0019$ & $0.0047 \pm 0.0012$ \\
\hline September & $-0.0005 \pm 0.0010$ & $-0.0080 \pm 0.0021$ & $0.0115 \pm 0.0030$ & $0.0156 \pm 0.0028$ \\
\hline October & $0.0110 \pm 0.0038$ & $0.0141 \pm 0.0034$ & $0.0151 \pm 0.0031$ & $0.0262 \pm 0.0044$ \\
\hline November & $0.0037 \pm 0.0008$ & $-0.0040 \pm 0.0025$ & $0.0145 \pm 0.0016$ & $0.0157 \pm 0.0020$ \\
\hline \multirow[t]{3}{*}{ December } & $0.0106 \pm 0.0022$ & $0.0031 \pm 0.0020$ & $0.0079 \pm 0.0019$ & $-0.0007 \pm 0.0014$ \\
\hline & \multicolumn{4}{|c|}{ average $\Delta C_{\mathrm{c}}$ mixing ratio difference \pm standard deviation $\Delta C_{\mathrm{c}}(\mathrm{ppm})$} \\
\hline & Night & Morning & Afternoon & Evening \\
\hline January & $1.01 \pm 0.27$ & $0.26 \pm 0.18$ & $1.99 \pm 0.34$ & $0.91 \pm 0.25$ \\
\hline February & $-0.71 \pm 0.21$ & $-0.19 \pm 0.19$ & $0.11 \pm 0.18$ & $-0.27 \pm 0.18$ \\
\hline March & $1.00 \pm 0.18$ & $2.84 \pm 0.60$ & $2.82 \pm 0.73$ & $2.35 \pm 0.36$ \\
\hline November & $1.76 \pm 0.26$ & $1.69 \pm 0.45$ & $2.19 \pm 0.64$ & $1.34 \pm 0.22$ \\
\hline December & $1.32 \pm 0.24$ & $1.05 \pm 0.15$ & $2.41 \pm 0.26$ & $0.65 \pm 0.13$ \\
\hline
\end{tabular}

$\Delta C_{\mathrm{m}}, \Delta C_{\mathrm{c}}$ : Difference in $\mathrm{CH}_{4}$ and $\mathrm{CO}_{2}$ mixing ratios between the mountain-top and the tall-tower station

494 derived as average value of each 2-h bias passing the WDS filter within the corresponding time period

495 (including the corresponding standard deviation). Night: 0000-0400 UTC; morning: 0800-1200 UTC;

496 afternoon: 1200-1600 UTC; evening: 2000-2400 UTC. The WDS filter is a meteorological conditional

497 filter described in Section 3.3.

499 These retained data are thought to best represent the regional atmospheric signal in a way

500 that allows for a direct comparison of the mountain-top mixing ratios with those

501 concurrently measured at the tall-tower station. Average $\Delta C_{\mathrm{m}}$ after WDS filtering

502 (Table 1) varied between $-0.0149 \pm 0.0022 \mathrm{ppm}(0800-1200$ UTC in August) and

$5030.0392 \pm 0.0041$ ppm (0800-1200 UTC in January). In September between 0000 and

$5040400 \mathrm{UTC}$, the average $\Delta C_{\mathrm{m}}$ bias was closest to zero $(-0.0005 \pm 0.0010 \mathrm{ppm})$. During the 
505 morning hours, the average $\Delta C_{\mathrm{m}}$ was often negative (tall-tower station observed higher 506 values than the mountain-top station), especially in summer. Average $\Delta C_{\mathrm{c}}$ after filtering 507 varied between $-0.71 \pm 0.21 \mathrm{ppm}(0000-0400$ UTC in February) and $2.84 \pm 0.60 \mathrm{ppm}$ 508 (0800-1200 UTC in March) and was $0.11 \pm 0.18$ ppm (1200-1600 UTC in February) in 509 the best case.

510 In addition to the bias calculations we also performed a correlation analysis with (a) the 511 WDS filtered 2-h mixing ratio averages and (b) the $5^{\text {th }}$ percentiles of $\mathrm{CH}_{4}$ and $\mathrm{CO}_{2}$ 512 mixing ratios measured at both sites. Fourteen-day running Pearson's correlation 513 coefficients for $\mathrm{CH}_{4}$ mixing ratios filtered with the $5^{\text {th }}$ percentile exceeded $R=0.7$ in $67 \%$ 514 of all cases. This means that in the majority of cases more than $\approx 50 \%$ (derived from $515 R^{2} \geq 0.7^{2}$ ) of the variance in the $\mathrm{CH}_{4}$ mixing ratios at the mountain top could be explained 516 by the concurrent tall-tower measurements and vice versa.

517 The WDS filter leaded to similarly high correlations between the mountain-top and the 518 tall-tower station $\mathrm{CH}_{4}$ mixing ratios $\left(R \geq 0.7\right.$ in $67 \%$ of the cases) as the $5^{\text {th }}$ percentile 519 (Fig. $10 \mathrm{~b}$ ). Weaker correlations $(R<0.7)$ could often be attributed to periods with 520 weakly varying atmospheric $\mathrm{CH}_{4}$ mixing ratios at both stations. Usually periods with 521 very high correlations were also characterised by offsets between the stations being close 522 to zero. The good overall agreement between both filtered time series indicates that $\mathrm{CH}_{4}$ 523 mixing ratios at the mountain-top station follow the same seasonal trend as $\mathrm{CH}_{4}$ mixing 524 ratios at the tall-tower station, but it was not possible to completely eliminate the offset at 525 the mountain-top station imposed by local sources and/or mountain flows, even after 526 screening 2-h averages with a WDS filter or filtering the $\mathrm{CH}_{4}$ data using the $5^{\text {th }}$ percentile 527 approach.

528 Wintertime $\mathrm{CO}_{2}$ mixing ratios at the two stations agreed rather well after applying the $5^{\text {th }}$ 529 percentile or the WDS filter, as is indicated by the high correlation coefficients (typically $530 R>0.7)$. From January to April, there was an excellent agreement of $\mathrm{CO}_{2}$ mixing ratios 531 between the tall-tower and the mountain-top station (Fig. $10 \mathrm{c}, \mathrm{d}$ ). During the growing 532 season, the relationship was weakest (usually with $0.3<R<0.6$, Fig. $10 \mathrm{~d}$ ). During 533 winter the relationship between $5^{\text {th }}$ percentiles of the $\mathrm{CO}_{2}$ mixing ratios measured at both 
534 stations was as good as the relationship between the WDS filtered 2-h average mixing 535 ratios, whereas in summer the WDS filtering usually did not retain any values.

536
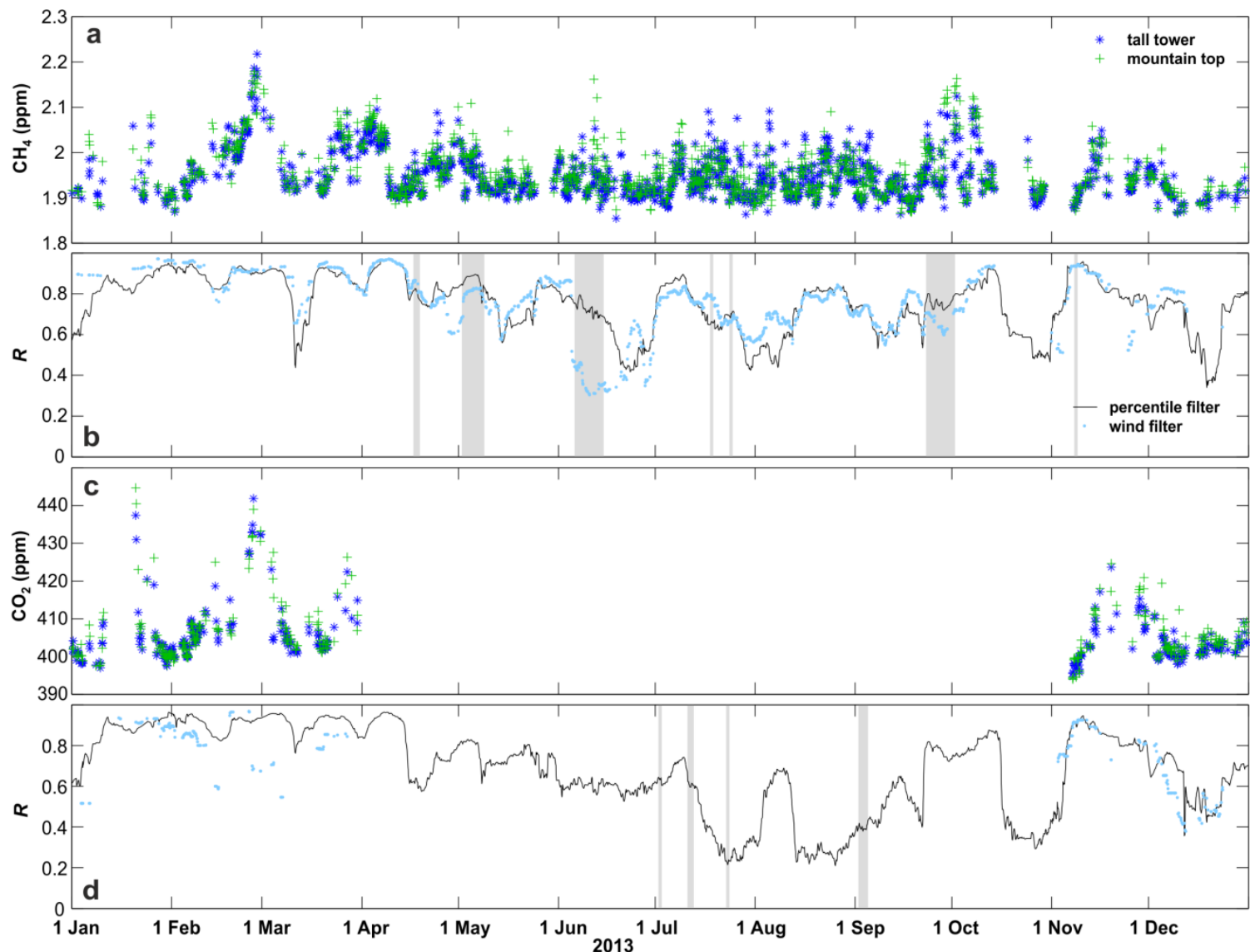

538 Fig. 10 Comparison of the $\mathrm{CH}_{4}(\mathbf{a})$ and $\mathrm{CO}_{2}$ (c) mixing ratios at the mountain-top (green crosses) and the

539 tall-tower (blue asterisk) station after the application of the WDS filter. Pearson's correlation coefficients $(R)$

540 between $5^{\text {th }}$ percentiles of mountain-top and tall-tower measurements (black solid line) and 2-h averages of

541 mountain-top and tall-tower measurements retained after WDS filtering (blue dots) calculated within a time

542 window of \pm 7 days around every measurement point are shown for $\mathrm{CH}_{4}(\mathbf{b})$ and $\mathrm{CO}_{2}(\mathbf{d})$, respectively. The

543 Pearson correlation coefficients are all significantly different from zero $(\mathrm{p}<0.01)$. Management activities

544 affecting the surrounding meadows are highlighted in grey in panels $\mathrm{b}$ and $\mathrm{d}$. The management activities at

545 the mountain-top station were: application of organic fertilizer or grazing of cattle on the pastures

546 surrounding the measurements (b) and harvests (d). 


\section{Discussion}

549 Precise measurements of $\mathrm{CO}_{2}$ and $\mathrm{CH}_{4}$ mixing ratios have been carried out at several 550 stations in Europe and North America already (e.g. Thompson et al. 2009, Göckede et al.

551 2010, Sun et al. 2010, Winderlich et al. 2010, Vermeulen et al. 2011, Lavaux et al. 2012,

552 Miles et al. 2012, Andrews et al. 2014). To the best of our knowledge, however, this

553 study is the first to discuss the measurements obtained at two stations in a paired-site

554 approach, comparing a tall-tower with a neighbouring $(\approx 28 \mathrm{~km}$ separation $)$ mountain-top

555 station at a similar elevation above sea level. Since local effects are usually not

556 represented well in atmospheric transport models it is essential to extract the regional

557 signal from mountain-top measurements. Thus, the key challenge for inverse modelling

558 in the comparison between tall-tower and mountain-top greenhouse gas mixing ratios is

559 the filtering of the dataset to remove local influences that only affect one but not the other

560 site. On the other hand, meteorologists trying to qualitatively and quantitatively

561 understand such local effects in complex terrain are typically interested in periods or in

562 meteorological conditions when differences between two sites are largest. In order to

563 address both aspects, we first discuss the extraction of the regional signal using the

564 filtering approach suggested in Section 3.3, and then address the meteorological

565 differences between the sites under conditions when local effects play an important role.

567 4.1 Extracting the Regional Signal

568 Two approaches were used to extract the regional signal from the time series of mixing 569 ratio measurements: (i) using a statistical percentile filter, and (ii) using a conditional 570 filter based on wind direction, wind speed, time of day, and season (WDS filter). An

571 alternative filtering approach, which was already used to screen data from well mixed air 572 masses, is time-of-day filtering (Göckede et al. 2010, Peters et al. 2010), which 573 exclusively uses well mixed afternoon conditions and nighttime measurements in the 574 residual layer well above the nocturnal boundary layer. More sophisticated statistical 575 approaches which have been used to filter mountain-top measurements are (i) short-term 576 variance filters and (ii) weighted median smoothers (Brooks et al., 2012). In our case, the

$5775^{\text {th }}$ percentile approach proved to be a suitable choice to filter outliers related to local $\mathrm{CH}_{4}$ 578 sources. However, this approach makes the implicit assumption that within a 2-hour time 
579 period the lower-than-average mixing ratios are most likely closest to the regional signal, 580 while higher-than-average mixing ratios are more likely to be outliers caused by local 581 sources. Using a $5^{\text {th }}$ percentile filter led to rather robust comparisons between tall-tower 582 and mountain-top sites for $\mathrm{CH}_{4}$ mixing ratios (Fig. 5). Its shortcomings, however, are its

583 relatively strong sensitivity to local sinks, its statistical and non-causal basis, and the fact 584 that there is no clear threshold that would establish the $5^{\text {th }}$ percentile as the best choice 585 everywhere. Contrastingly, the second approach - the WDS filter - uses conditional

586 criteria that are easier to understand in the context of impacts of the local topography and 587 local surface fluxes. For $\mathrm{CH}_{4}$, both filtering approaches seem to be useful, whereas in the 588 case of $\mathrm{CO}_{2}$ none of the filters worked well during the growing season (Fig. 10), 589 indicating that the regional signal is too strongly altered by local influences to be 590 extracted with a WDS filter.

$592 \quad 4.2$ The Importance of Local Effects

593 4.2.1 Terrain Driven Effects on Greenhouse Gas Mixing Ratios

594 The accumulation of $\mathrm{CH}_{4}$ and other trace gases in the nocturnal boundary layer at valley595 bottom sites during the night is a general pattern found in diurnal cycles of mixing ratio 596 measurements and has been used before to determine regional-scale $\mathrm{CH}_{4}$ fluxes (e.g., 597 Stieger et al. 2015). At the mountain top, cold air drainage flows prevent the build-up of a 598 deep, stable nocturnal boundary layer and thus the boundary layer extends 200-300 m 599 above the valley bottom, even in broad valleys such as the Swiss Plateau (cf. Eugster and 600 Siegrist, 2000; see also Stieger et al., 2015). Hence, although our mountain-top 601 measurements were only performed at 4-m height above ground surface, the diurnal 602 courses of $\mathrm{CH}_{4}$ and $\mathrm{CO}_{2}$ mixing ratios rather followed that of the tall-tower site (Figs. 5 603 and 6) than that of a valley-bottom site (Fig. 7). This indicates that the mountain-top 604 station - similarly to the tall-tower station - remains above the stable nocturnal boundary 605 layer of the surrounding valleys, where agriculturally driven methane emissions lead to a 606 substantial increase of methane during the night (Fig. 7). Consequently, both sites were 607 decoupled from the conditions at the valley floor during the night. This agrees well with 608 mobile measurements that were performed along the slopes of the Reuss valley and up to 
609 the Früebüel mountain-top site (Bamberger et al. 2014) which clearly showed that the

610 nocturnal boundary-layer depth is only between $100 \mathrm{~m}$ and $200 \mathrm{~m}$ deep during clear

611 summer days, while the Früebüel mountain-top site is located almost $500 \mathrm{~m}$ above the

612 valley floor. Considering the low sampling height above ground, however, the mountain-

613 top site is located in the local surface layer.

614 Greenhouse gas mixing ratios at the tall-tower site showed a well-known increase of

615 mixing ratios in the late morning with the onset of daytime convective mixing (Davis et

616 al. 2003) which was virtually absent at the mountain-top site. The absence of the late

617 morning peak at the mountain top can be explained by its location on top of a mountain

618 ridge on the easterly side of the Reuss valley (Bamberger et al. 2014). The onset of

619 daytime convective mixing and vertical advection of nighttime pollution along the

620 warmer hillslopes is a pattern that is common to mountainous regions (Gohm et al. 2009,

621 Schnitzhofer et al. 2014). Considering the diurnal cycle of greenhouse gas mixing ratios,

622 the tall-tower station (nominally $212 \mathrm{~m}$ a.g.l.) also profits from its position on a local hill

623 that removes the tower top from the valley bottom (where $\mathrm{CH}_{4}$ and $\mathrm{CO}_{2}$ accumulates

624 during the night) by an additional $\approx 300 \mathrm{~m}$ : the tower base is at $797 \mathrm{~m}$ a.s.l., whereas the

625 flat areas surrounding the locality are at $463 \mathrm{~m}$ (Lake Baldegg) to $504 \mathrm{~m}$ a.s.l. (Lake

626 Sempach). Without this additional topographic height, more pronounced diurnal cycles in

$627 \mathrm{CH}_{4}$ and $\mathrm{CO}_{2}$ mixing ratios would be expected at the tall-tower site: Winderlich et al.

628 (2014) found that at the highest level (301 $\mathrm{m}$ above ground) of the Zotino tower, Siberia,

629 occasional nocturnal increases in $\mathrm{CH}_{4}$ mixing ratios occur.

630 All these considerations suggest that for both mountain-top and tall-tower sites it is not

631 the height of a measurement from the local ground that matters, but the larger-scale 632 topographic context, and thus the altitude above the topographic reference elevation, 633 which is typically the bottom of a larger and broader valley where nocturnal 634 accumulation of greenhouse gases takes place.

\section{4.2.2 Effects of Local Flow}

636 Flows at the tall-tower and the mountain-top stations showed both a strong channelling 637 along the two main wind directions (north-east and south-west) and minor contributions 638 from other directions, mostly in combination with low wind speeds. On the other hand, 
639 there was a directional shift between the main wind directions at the mountain-top site 640 (which was turned anti-clockwise) as compared with the tall-tower site. However, such a

641 rotation of the flow between the surface and the mid-boundary layer is well known as the

642 Ekman spiral (e.g. Holton 2004). Due to the well-known natural increase of wind speed

643 with height above surface, wind speeds within the surface layer measured at $2 \mathrm{~m}$ a.g.l. at

644 the mountain-top site were considerably lower than those at the tall-tower site (at $212 \mathrm{~m}$

645 a.g.l.) In addition, wind speeds at the tall-tower site were maximal during the night,

646 whereas they were lowest during the night at the mountain-top site, at least during 647 summer (Oney et al. 2015).

648 At the mountain top, flow from south-easterly direction was occasionally stronger (up to $64910 \mathrm{~m} \mathrm{~s}^{-1}$ ) than flow from other directions. These high wind speeds usually occurred in 650 combination with high temperatures and persistent wind directions (data not shown) and 651 indicated the influence of foehn winds (warm and dry southerly winds across the Alps). 652 The influence of foehn winds at the mountain-top station is plausible as it is located near 653 the main axis of the Reuss Valley, one of the main foehn valleys in Switzerland (Seibert 654 1990), whereas the tall-tower station is much more sheltered against the southerly flow 655 by Mount Rigi and other mountain ridges and is further away from the Alps. At the 656 mountain-top station, wind directions outside the usual easterly or westerly directions 657 were more frequent than at the tall-tower station but generally weak (mostly $<2 \mathrm{~m} \mathrm{~s}^{-1}$ ), 658 suggesting thermally induced south-westerly flows along the slopes of the Zugerberg 659 mountain ridge and larger scale northerly plain-to-mountain flows (Lugauer and Winkler 660 2005), a phenomenon commonly referred to as Alpine pumping. While easterly (down661 slope) winds were seen predominantly during night-time, westerly (up-slope) winds were 662 more frequent during the day, agreeing with the typical picture of diurnal mountain winds 663 (Whiteman 2000) in the surface layer. These findings agree with the findings by Oney et 664 al. (2015) that the local environment influences prevailing wind directions more at the 665 mountain-top station than at the tall-tower station.

\section{4.2.3 The Effect of Local Sources and Sinks}

667 During time periods when the ETH research station and its farmstead buildings were in 668 upwind direction of the mountain-top site the offset between both stations was $0.065 \mathrm{ppm}$ 
669 on average, whereas it was much lower $(<0.01 \mathrm{ppm})$ for all other wind directions (see 670 Fig. S1). The small directional deviation between the sector with highest $\mathrm{CH}_{4}$ mixing 671 ratios and the farmstead buildings (seen in Fig. S1) relates to the influence of local terrain. 672 The close farmstead obviously acted as a source of $\mathrm{CH}_{4}$ which considerably influenced 673 the mixing ratios when the flow came from that direction (Figs. S1 and 8). With higher 674 wind speeds and south-easterly flow, $\mathrm{CH}_{4}$ and $\mathrm{CO}_{2}$ mixing ratios at the mountain-top site 675 were typically lower than those at the tall-tower site (Figs. 8 and 9). This indicates that 676 the mountain-top station observes relatively clean free-tropospheric air masses 677 descending in the lee of the Alps during foehn as opposed to the tall-tower station 678 measuring planetary boundary-layer air. Since foehn wind tends to follow the terrain 679 similarly to hydraulic flows, our assumption that the same elevation above sea level can 680 be compared fails under such special conditions where altitude above the topographic 681 reference surface becomes more relevant than the absolute elevation. Additionally, during 682 nighttime and in winter, when vertical mixing is generally weaker, mixing ratios at wind 683 speeds $<2 \mathrm{~m} \mathrm{~s}^{-1}$ were often larger at the mountain-top as compared to the tall-tower 684 station, especially with westerly up-slope winds and northerly winds which most likely 685 originated from lower parts of the valley. Thus, with the WDS filter all conditions with (a) 686 flow from the farmstead, (b) wind directions and speeds associated with foehn, and (c) 687 during times with reduced vertical mixing, wind speeds $<2 \mathrm{~m} \mathrm{~s}^{-1}$ and northerly or 688 westerly wind directions were removed from the time series. When wind speeds are low $689\left(0-1 \mathrm{~m} \mathrm{~s}^{-1}\right)$, wind directions are often not properly defined or very variable. This could 690 explain why $\mathrm{CH}_{4}$ mixing ratios at wind speeds $<1 \mathrm{~m} \mathrm{~s}^{-1}$ are higher at the mountain top 691 even if wind direction does not include the local farmstead. Moreover, a strong northerly 692 or westerly component in the flow means that the air mass passed the Zugerberg 693 mountain ridge where other farmsteads are located. During periods of low solar radiation, 694 weak turbulence, and low wind speeds, the influences from more remote farmsteads 695 could be increased, which could explain the higher $\mathrm{CH}_{4}$ mixing ratios observed at the 696 mountain-top station.

697 Periods when $\mathrm{CO}_{2}$ mixing ratios were higher at the mountain-top station than those at the 698 tall-tower site did not show such pronounced wind-direction dependence as did $\mathrm{CH}_{4}$. In 699 spring and summer/autumn, the difference between $\mathrm{CO}_{2}$ mixing ratios at the mountain- 
700 top and the tall-tower station was typically highest with lower wind speeds $<2 \mathrm{~m} \mathrm{~s}^{-1}$ and

701 reduced vertical mixing (evening, night). As the vegetation surrounding the mountain-top

702 site is covered by grassland and forests, it acted both as a source (respiration) and a

703 strong sink (photosynthesis) of $\mathrm{CO}_{2}$ depending on time of day or season and management

704 (Zeeman et al. 2010). This generally limited the capability to distil the anthropogenic

$705 \mathrm{CO}_{2}$ signal out of the $\mathrm{CO}_{2}$ mixing ratio time series. Here an increased measurement

706 height above the local surface may help to reduce the strong influence from the

707 vegetation (e.g. Bakwin et al. 1995, 1998). Alternatively, there are methods to estimate

708 regional fluxes based on vertical gradients of mixing ratios between the atmospheric

709 boundary layer and the free troposphere at tower sites (e.g. Bakwin et al. 2004, Crevoisier

710 et al. 2006). In a well-mixed atmospheric boundary layer, flux-gradient relationships

711 (Monin and Obukhov 1954, Moeng and Wyngaard 1984, 1989) have been used to adjust

712 for biases introduced by low measurement heights (Bakwin et al. 2004). In winter, $\mathrm{CO}_{2}$

713 mixing ratios at the mountain-top were often higher than at the tall-tower site with flows

714 from the farmstead and flows from northerly or westerly directions, similarly to $\mathrm{CH}_{4}$

715 mixing ratios. These high biases were most frequent during periods of reduced vertical

716 mixing and thus were removed from our analysis.

717 In summary, our comparison between a tall-tower site and a mountain-top site provided

718 evidence that the regional signal of $\mathrm{CH}_{4}$ mixing ratios can be extracted from the time

719 series even under the presence of geographically constrained local sources. However, a

720 bias of approximately $0.01 \mathrm{ppm}$ in the $\mathrm{CH}_{4}$ mixing ratio has to be taken into account. It

721 remains much more challenging to do the same with $\mathrm{CO}_{2}$ mixing ratios due to the

722 dominance of the local biogenic signal present in the measurements when plant

723 photosynthesis and ecosystem respiration are most active.

724

\section{Conclusions}

726 Atmospheric $\mathrm{CO}_{2}$ and $\mathrm{CH}_{4}$ observations at a mountain-top site have been compared to 727 measurements at a neighbouring tall-tower site (within $28.4 \mathrm{~km}$ horizontal distance) at a 728 similar elevation above sea level. Although the airflow was significantly perturbed 729 locally at the mountain-top site, $\mathrm{CH}_{4}$ mixing ratios were quite similar to those at the tall- 
730 tower site, except for peak values. Average mountain-top and tall-tower $\mathrm{CH}_{4}$ mixing

731 ratios showed good agreement, with an average $\mathrm{CH}_{4}$ bias between the two stations that 732 was around $0.01 \mathrm{ppm}$, after applying a filter to select for favorable wind direction, wind 733 speeds, time of day and season at the mountain-top site, and $5^{\text {th }}$ percentiles of the $2-\mathrm{h}$

734 frequency distribution of $\mathrm{CH}_{4}$ mixing ratios at both sites. Peak mixing ratios of unfiltered 735 data, however, were clearly influenced more by local $\mathrm{CH}_{4}$ sources at the mountain top 736 site than at the tall-tower site. Consequently, it was possible to minimize, but not to 737 completely remove, the influence of local agricultural $\mathrm{CH}_{4}$ sources by choosing an 738 appropriate filter. Hence, we conclude that, at least in absence of local sources, a 739 mountain-top station can provide greenhouse gas observations with similar regional 740 representativeness as a tall-tower station. Geographically well-defined $\mathrm{CH}_{4}$ sources may 741 be acceptable to a certain degree as their influence can be removed with appropriate 742 filtering. However, it is generally preferable to choose the location of mountain-top sites 743 in a way that local sources are virtually absent.

744 For $\mathrm{CO}_{2}$, however, the usefulness of mountain-top mixing ratio measurements may be 745 more limited for inverse modelling, especially during summer, when vegetation and soils 746 cause a more pronounced diurnal cycle at the mountain top than on the top of a tall tower.

747 Since these diurnal and seasonal signals are strong, a filter based on local wind conditions, 748 time of day, and season is not able to remove all local influences of the vegetation at the 749 mountain-top site. At sites where the larger-scale (far-field) signal to local-scale noise 750 ratio remains an issue, an increased measurement height should be considered, leading to 751 a dilution and damping of the local-scale noise. Being aware of such limitations, we 752 conclude that a carefully selected mountain-top site still can be considered a suitable 753 alternative for a tall-tower station. Mountain sites have a similar potential for continuous 754 long-term monitoring, and could complement tall-tower stations, especially in 755 mountainous terrain.

757 Acknowledgements The study was financially supported by the Swiss National Science Foundation under 758 the grant number CRSII2_136273. The authors acknowledge the staff members of the ETH research station 759 for the agricultural management at the mountain-top site and the technicians of the ETH Grassland

760 Sciences Group, Peter Plüss and Thomas Baur, for their assistance during installation and setup of the 761 measurement station at Früebüel. We acknowledge the tower-site installation at Beromünster designed by 
762 Rüdiger Schanda, Peter Nyfeler, Hanspeter Moret, Samuel Marending from the University of Bern and 763 installed by Cablex AG (Bern, Switzerland). Further, the authors acknowledge Swisscom for granting 764 access to the tall tower, and the local authorities for the construction permit. Susanne Burri, Carmen

765 Emmel, Anna Gilgen, Lukas Hörtnagl and Lutz Merbold from the Grassland Sciences Group are 766 acknowledged for their helpful scientific discussions.

767 
Andrews AE, Kofler JD, Trudeau ME, Williams JC, Neff DH, Masarie KA, Chao DY, Kitzis DR, Novelli PC, Zhao CL, Dlugokencky EJ, Lang PM, Crotwell MJ, Fischer ML, Parker MJ, Lee JT, Baumann DD, Desai AR, Stanier CO, De Wekker SFJ, Wolfe DE, Munger JW, Tans PP (2014) $\mathrm{CO}_{2}, \mathrm{CO}$, and $\mathrm{CH}_{4}$ measurements from tall towers in the NOAA Earth System Research Laboratory's Global Greenhouse Gas Reference Network: instrumentation, uncertainty analysis, and recommendations for future high-accuracy greenhouse gas monitoring efforts. Atmos Meas Tech 7:647-687. doi: 10.5194/amt-7-647-2014

Bakwin PS, Davis KJ, YI C, Wofsy SC, Munger JW, L. Haszpra L, Barcza Z (2004) Regional carbon dioxide fluxes from mixing ratio data. Tellus 56B: 301-311.

Bakwin PS, Tans PP, Hurst DF, Zhao C (1998) Measurements of carbon dioxide on very tall towers: results of the NOAA/CMDL program. Tellus 50B: 401-415.

Bakwin PS, Tans PP, Zhao C, Ussler W, Quesnell E (1998) Measurements of carbon dioxide on a very tall tower. Tellus 47B: 535-549.

Bamberger I, Stieger J, Buchmann N, Eugster W (2014) Spatial variability of methane: Attributing atmospheric concentrations to emissions. Environ Pollut 190:65-74. doi: 10.1016/j.envpol.2014.03.028

Beck V, Chen H, Gerbig C, Bergamaschi P, Bruhwiler L, Houweling S, Röckmann T, Kolle O, Steinbach J, Koch T, Sapart CJ, van der Veen C, Frankenberg C, Andreae MO, Artaxo P, Longo KM, Wofsy SC (2012) Methane airborne measurements and comparison to global models during BARCA. J Geophys Res 117:D15310. doi: 10.1029/2011JD017345

Berhanu TA, Satar E, Schanda R, Nyfeler P, Moret H, Brunner D, Oney B, Leuenberger M (2016) Measurements of greenhouse gases at Beromünster tall tower station in Switzerland. Atmos Meas Tech 9: 2603-2614. doi:10.5194/amt-9-2603-2016 2957. doi:10.1214/10-AOS799

Brooks BGJ, Desai AR, Stephens BB, Bowling DR, Burns SP, Watt AS, Heck SL, Sweeney C (2012) Assessing filtering of mountaintop $\mathrm{CO}_{2}$ mole fractions for application to inverse models ob biosphere-atmosphere carbon exchange, Atmos Chem Phys 12, 2099-2115. doi: 10.5194/acp-122099-2012

Buchwitz M, Reuter M, Schneising O, Boesch H, Guerlet S, Dils B, Aben I, Armante R, Bergamaschi P, Blumenstock T, Bovensmann H, Brunner D, Buchmann B, Burrows JP, Butz A, Chédin A, Chevallier F, Crevoisier CD, Deutscher NM, Frankenberg C, Hase F, Hasekamp OP, Heymann J, Kaminski T, Laeng A, Lichtenberg G, De Mazière M, Noël S, Notholt J, Orphal J, Popp C, Parker R, Scholze M, Sussmann R, Stiller GP, Warneke T, Zehner C, Bril A, Crisp D, Griffith DWT, Kuze A, O'Dell C, Oshchepkov S, Sherlock V, Suto H, Wennberg P, Wunch D, Yokota T, Yoshida Y (2013) The Greenhouse Gas Climate Change Initiative (GHG-CCI): Comparison and quality assessment of near-surface-sensitive satellite-derived $\mathrm{CO}_{2}$ and $\mathrm{CH}_{4}$ global data sets. Remote Sens Environ 162:344362. doi: 10.1016/j.rse.2013.04.024 
Collaud Coen M, Praz C, Haefele A, Ruffieux D, Kaufmann P, Calpini B (2014) Determination and climatology of the planetary boundary layer height above the Swiss plateau by in situ and remote sensing measurements as well as by the COSMO-2 model. Atmos Chem Phys 14: 13205-13221, doi: 10.5194/acp-14-13205-2014

814 Crevoisier C, Gloor M, Gloaguen E, Horowitz LW, Sarmiento JL, Sweeney C, Tans PP (2006) A direct carbon budgeting approach to infer carbon sources and sinks. Design and synthetic application to complement the NACP observation network. Tellus B 58:366-375. doi: 10.1111/j.16000889.2006.00214.x

Davis KJ, Bakwin PS, Yi C, Berger BW, Zhao C, Teclaw RM, Isebrands JG (2003) The annual cycles of $\mathrm{CO}_{2}$ and $\mathrm{H}_{2} \mathrm{O}$ exchange over a northern mixed forest as observed from a very tall tower. Glob Change Biol 9: 1278-1293.

Dlugokencky EJ, Nisbet EG, Fisher R, Lowry D (2011) Global atmospheric methane: budget, changes and dangers. Phil Trans R Soc A 369:2058-2072. doi: 10.1098/rsta.2010.0341

Eugster W, Siegrist FC (2000) The influence of nocturnal $\mathrm{CO}_{2}$ advection on $\mathrm{CO}_{2}$ flux measurements. Basic

Frankenberg C, Bergamaschi P, Butz A, Houweling S, Meirink JF, Notholt J, Petersen AK, Schrijver H, Warneke T, Aben I (2008) Tropical methane emissions: A revised view from SCIAMACHY onboard ENVISAT. Geophys Res Lett 35: L15811. doi: 10.1029/2008GL034300

Frankenberg C, Meirink JF, van Weele M, Platt U, Wagner T (2005) Assessing methane emissions from global space-borne observations. Science 308: 1010-1014. doi: 10.1126/science.1106644

830 Frankenberg C, Pollock R, Lee RAM, Rosenberg R, Blavier J-F, Crisp D, O'Dell CW, Osterman GB, Roehl C, Wennberg PO, Wunch D (2015) The Orbiting Carbon Observatory (OCO-2): spectrometer performance evaluation using pre-launch direct sun measurements. Atmos Meas Tech 8: 301-313. doi:10.5194/amt-8-301-2015

Gerbig C, Körner S, Lin JC (2008) Vertical mixing in atmospheric tracer transport models: error characterization and propagation. Atmos Chem Phys 8: 591-602. doi: 10.5194/acp-8-591-2008

Gloor M, Bakwin P, Hurst D, Lock L, Draxler R, Tans P (2001) What is the concentration footprint of a tall tower? J Geophys Res 106, 17831-17840. doi: 10.1029/2001JD900021

Gohm A, Harnisch F, Vergeiner J, Obleitner F, Schnitzhofer R, Hansel A, Fix A, Neininger B, Emeis S, Schäfer K (2009) Air Pollution Transport in an Alpine Valley: Results From Airborne and GroundBased Observations. Boundary-Layer Meteorol 131: 441-463. doi:10.1007/s10546-009-9371-9

844 Holton JR (2004) An Introduction to Dynamic Meteorology, Fourth Ed. Elsevier Academic Press, London, 845 England, pp 535.

846 Imer D, Merbold L, Eugster W, Buchmann N (2013) Temporal and spatial variations of soil $\mathrm{CO}_{2}, \mathrm{CH}_{4}$ and $\mathrm{N}_{2} \mathrm{O}$ fluxes at three differently managed grasslands. Biogeosciences 10: 5931-5945. doi: 10.5194/bg10-5931-2013 

Long-term greenhouse gas measurements from aircraft. Atmos Meas Tech 6: 511-526. doi:10.5194/amt-6-511-2013, 2013. Impact of optimized mixing heights on simulated regional atmospheric transport of $\mathrm{CO}_{2}$. Atmos Chem Phys 14: 7149-7172. doi: 10.5194/acp-14-7149-2014.

Kuze A, Suto H, Nakajima M, Hamazaki T (2009) Thermal and near infrared sensor for carbon observation Fourier-transform spectrometer on the Greenhouse Gases Observing Satellite for greenhouse gases monitoring. Appl Opt 48: 6716-6733.

Lauvaux T, Schuh AE, Bocquet M, Wu L, Richardson S, Miles N, Davis KJ (2012) Network design for mesoscale inversions of $\mathrm{CO}_{2}$ sources and sinks. Tellus B 64: 17980.

Lee TR, de Wekker SFJ, Sandip P, Andrews AE, Kofler J (2015) Meteorological controls on the diurnal variability of carbon monoxide mixing ratio at a mountaintop monitoring site in the Appalachian Mountains. Tellus B 67: 25659.

863 Lin JC, Gerbig C (2005) Accounting for the effect of transport errors on tracer inversions. Geophys Res

864 Lett 32:L01802. doi: 10.1029/2004GL021127

Lugauer M, Winkler P (2005) Thermal circulation in South Bavaria - climatology and synoptic aspects. Meteorol Z 14: 15-30. doi: 10.1127/0941-2948/2005/0014-0015

McKain K, Wofsy SC, Nehrkorn T, Eluszkiewicz J, Ehleringer JR, Stephens BB (2012) Assessment of ground-based atmospheric observations for verification of greenhouse gas emissions from an urban region. Proc Natl Acad Sci USA. doi: 10.1073/pnas.1116645109

Merbold L, Eugster W, Stieger J, Zahniser M, Nelson D, Buchmann N (2014) Greenhouse gas budget $\left(\mathrm{CO}_{2}, \mathrm{CH}_{4}\right.$ and $\left.\mathrm{N}_{2} \mathrm{O}\right)$ of intensively managed grassland following restoration. Glob Change Biol 20: 1913-1928, doi:10.1111/gcb.12518.

Miles NL, Richardson SJ, Davis KJ, Lauvaux T, Andrews AE, West TO, BandaruV, Crosson ER (2012) Large amplitude spatial and temporal gradients in atmospheric boundary layer $\mathrm{CO}_{2}$ mole fractions detected with a tower-based network in the U.S. upper Midwest. J Geophys Res 117: G01019, doi:10.1029/2011JG001781.

Moeng C-H, Wyngaard JC (1984) Statistics of Conservative Scalars in the Convective Boundary Layer. J Atmos Sci 41(21): 3161-3169.

Moeng C-H, Wyngaard JC (1989) Evaluation of Turbulent Transport and Dissipation Closures in SecondOrder Modeling. J Atmos Sci 46(14): 2311-2330.

884 Myhre, G., D. Shindell, F.-M. Bréon, W. Collins, J. Fuglestvedt, J. Huang, D. Koch, J.-F. Lamarque, D.

885 Lee, B. Mendoza, et al. (2013), Anthropogenic and Natural Radiative Forcing, in Climate Change 886 2013: The Physical Science Basis. Contribution of Working Group I to the Fifth Assessment Report 
of the Intergovernmental Panel on Climate Change, edited by T. F. Stocker, D. Qin, et al., pp. 659740, Cambridge University Press, Cambridge, United Kingdom and New York, NY, USA.

Nisbet E, Weiss R (2010) Atmospheric science. Top-down versus bottom-up. Science 328: 1241-1243. doi: $10.1126 /$ science. 1189936

891

892

893

894

895

896

897

898

899

900

901

902

903

904

905

906

907

908

909

910

911

912

913

914

915

916

917

918

919

920

921

922

923

924

925

926

927

Oney B, Henne S, Gruber N, Leuenberger M, Bamberger I, Eugster W, Brunner D (2015) The CarboCount CH sites: characterization of a dense greenhouse gas observation network. Atmos Chem Phys 15: 11147-11164. doi:10.5194/acp-15-11147-2015

Peters W, Krol MC, van der Werf GR, Houweling S, Jones CD, Hughes J, Schaefer K, Masarie KA, Jacobson AR, Miller JB, Cho CH, Ramonet M, Schmidt M, Ciattaglia L, Apadula F, Heltai D, Meinhardt F, di Sarra AG, Piacentino S, Sferlazzo D, Aalto T, Hatakka J, Strom J, Haszpra L, Meijer HAJ, van der Laan S, Neubert REM, Jordan A, Rodo X, Morgui J-A, Vermeulen AT, Popa E, Rozanski K, Zimnoch M, Manning AC, Leuenberger M, Uglietti C, Dolman AJ, Ciais P, Heimann M, Tans PP (2010) Seven years of recent European net terrestrial carbon dioxide exchange constrained by atmospheric observations. Glob Change Biol 16: 1317-1337. doi:10.1111/j.13652486.2009.02078.x

Pillai D, Gerbig C, Ahmadov R, Rödenbeck C, Kretschmer R, Koch T, Thompson R, Neininger B, Lavrié J V. (2011) High-resolution simulations of atmospheric $\mathrm{CO}_{2}$ over complex terrain - representing the Ochsenkopf mountain tall tower. Atmos Chem Phys 11:7445-7464. doi: 10.5194/acp-11-7445-2011

Rotach MW, Andretta M, Calanca P, Weigel AP, Weiss A (2007) Boundary layer characteristics and turbulent exchange mechanisms in highly complex terrain. Acta Geophys 56:194-219. doi: 10.2478/s11600-007-0043-1

Rotach MW, Wohlfahrt G, Hansel A, Reif M, Wagner J, Gohm A (2013) The world is not flat implications for the global carbon balance. Bull Am Meteorol Soc 95:1021-1028.

Schnitzhofer R, Norman M, Wisthaler A, Vergeiner J, Harnisch F, Gohm A, Obleitner F, Fix A, Neininger B, and Hansel A (2009) A multimethodological approach to study the spatial distribution of air pollution in an Alpine valley during wintertime, Atmos Chem Phys 9: 3385-3396. doi:10.5194/acp-93385-2009

Schuck TJ, Ishijima K, Patra PK, Baker AK, Machida T, Matsueda H, Sawa Y, Umezawa T, Brenninkmeijer CAM, Lelieveld J (2012) Distribution of methane in the tropical upper troposphere measured by CARIBIC and CONTRAIL aircraft. J Geophys Res - Atmos 117: D19304. doi: 10.1029/2012JD018199

Seibert P (1990) South foehn studies since the ALPEX experiment. Meteorol Atmos Phys 43: 91-103. doi: 10.1007/BF01028112

Smallman TL, Williams M, Moncrieff JB (2014) Can seasonal and interannual variation in landscape $\mathrm{CO}_{2}$ fluxes be detected by atmospheric observations of $\mathrm{CO}_{2}$ concentrations made at a tall tower? Biogeosciences 11: 735-747. doi: 10.5194/bg-11-735-2014

Stieger J, Bamberger I, Buchmann N, Eugster W (2015) Validation of farm-scale methane emissions using nocturnal boundary-layer budgets. Atmos Chem Phys 15: 14055-14069. doi:10.5194/acp-15-140552015

Sun J, Oncley SP, Burns SP, Stephens BB, Lenschow DH, Campos, T, Russel KM, Schimel, DS, Sacks WJ, De Wekker SFJ, Lai CT, Lamb B, Ojima D, Ellsworth PZ, Sternberg LSL, Zhong S, Clements 
C, Moore DJP, Anderson DE, Watt AS, Hu J, Tschudi M, Aulenbach S, Allwine E, Coons T (2010) A multiscale and multidisciplinary investigation of ecosystem-atmosphere $\mathrm{CO}_{2}$ exchange over the Rocky Mountains of Colorado, Bull Amer Meteorol Soc 91: 209-230

Thompson RL, Manning AC, Gloor E, Schultz U, Seifert T, Hänsel F, Jordan A, Heimann M (2009) In-situ measurements of oxygen, carbon monoxide and greenhouse gases from Ochsenkopf tall tower in Germany. Atmos Meas Tech 2: 573-591. doi: 10.5194/amt-2-573-2009

Tolk LF, Meesters AGCA, Dolman AJ, Peters W (2008) Modelling representation errors of atmospheric $\mathrm{CO}_{2}$ mixing ratios at a regional scale. Atmos Chem Phys 8: 6587-6596, doi: 10.5194/acp-8-65872008

van der Molen MK, Dolman AJ (2007) Regional carbon fluxes and the effect of topography on the variability of atmospheric $\mathrm{CO}_{2}$, J Geophys Res 112: D01104, doi:10.1029/2006JD007649

Vermeulen AT, Hensen A, Popa ME, van den Bulk WCM, Jongejan PAC (2011) Greenhouse gas observations from Cabauw Tall Tower (1992-2010). Atmos Meas Tech 4: 617-644. doi: 10.5194/amt-4-617-2011

Villani MG, Bergamaschi P, Krol M, Meirink JF, Dentener F (2010) Inverse modeling of European $\mathrm{CH}_{4}$ emissions: sensitivity to the observational network. Atmos Chem Phys 10:1249-1267. doi: 10.5194/acp-10-1249-2010

Wanner H, Furger M (1990) The Bise - Climatology of a Regional Wind North of the Alps. Meteorol

Whiteman D (2000) Diurnal mountain winds. Mountain Meteorology. Oxford University Press, New York, Atmos Phys 43: 105-115.

Winderlich J, Chen H, Gerbig C, Seifert T, Kolle O, Lavrič J V, Kaiser C, Höfer A, Heimann M (2010) Continuous low-maintenance $\mathrm{CO}_{2} / \mathrm{CH}_{4} / \mathrm{H}_{2} \mathrm{O}$ measurements at the Zotino Tall Tower Observatory (ZOTTO) in Central Siberia. Atmos Meas Tech 3: 1113-1128. doi: 10.5194/amt-3-1113-2010

Winderlich J, Gerbig C, Kolle O, Heimann M (2014) Inferences from $\mathrm{CO}_{2}$ and $\mathrm{CH}_{4}$ concentration profiles at the Zotino Tall Tower Observatory (ZOTTO) on regional summertime ecosystem fluxes. Biogeosciences 11: 2055-2068. doi: 10.5194/bg-11-2055-2014

Xiong X, Barnet CD, Zhuang Q, Machida T, Sweeney C, Patra PK (2010) Mid-upper tropospheric methane in the high Northern Hemisphere: Spaceborne observations by AIRS, aircraft measurements, and model simulations. J Geophys Res 115: D19309. doi: 10.1029/2009JD013796

Zeeman MJ, Hiller R, Gilgen AK, Michna P, Plüss P, Buchmann N, Eugster W (2010) Management and climate impacts on net $\mathrm{CO}_{2}$ fluxes and carbon budgets of three grasslands along an elevational gradient in Switzerland. Agr For Meteorol 150: 519-530. doi: 10.1016/j.agrformet.2010.01.011 


\title{
Supplementary Material: Observations of atmospheric methane and carbon dioxide mixing ratios: Tall-tower or mountain-top stations?
}

\author{
Ines Bamberger · Brian Oney · Dominik Brunner · Stephan Henne - Markus Leuenberger · \\ Nina Buchmann · Werner Eugster* \\ * ETH Zurich, Universitätstrasse 2, 8092 Zurich, Switzerland, phone +41-44-632-6847, \\ e-mail eugsterw@ethz.ch
}

S1 Management Activities at the Mountain-Top Site

Table S1 Management activities at the grasslands surrounding the FRU mountain-top station

\begin{tabular}{lll}
\hline Date in 2013 & Management activity & Details \\
\hline 17-18 April & organic fertilizer & solid \\
2-8 May & grazing & suckler cows (25), calves (24) \\
6-14 June & grazing & cows (34) \\
1-2 July & cutting & 0.68 ha \\
11-12 July & cutting & 0.71 ha \\
18 July & organic fertilizer & solid \\
23 July & cutting & 3.28 ha \\
24 July & organic fertilizer & liquid \\
2-4 September & cutting & 0.68 ha \\
23 September-2 October & grazing & cows (34) \\
7-13 November & grazing & sheep (15) \\
\hline
\end{tabular}

\section{S2 Origin of Methane Emissions}

10 To determine whether the local methane sources at the mountain-top station are diffuse or attributable to a specific source we analyzed the dependence of the between-site differences $\left(\Delta C_{m}=\right.$ $\left.C_{m, \mathrm{FRU}}-C_{m, \mathrm{BER}}\right)$ on the wind direction at the mountain top (FRU). This was done both for twohourly average $\mathrm{CH}_{4}$ mixing ratios and for the $5^{\text {th }}$ percentiles of the two-hourly frequency distribution (Fig. S1). For average $\mathrm{CH}_{4}$ mixing ratios these differences remained generally below $0.02 \mathrm{ppm}$ for any wind direction, except for southerly winds from the direction of the ETH research station when average mixing ratios at the FRU were considerably higher (up to $0.065 \mathrm{ppm}$ ).

This pattern was not restricted to dates when cattle were grazing on the pastures surrounding the FRU measurement station, thus indicating the general influence of $\mathrm{CH}_{4}$ emissions from the nearby farmstead in the south. Evaluating the between-site differences for the $5^{\text {th }}$ percentiles instead of the average mixing ratios, however, showed no comparable dependence on wind direction (Fig. S1). Thus the percentile approach, which assumes that the lower edge of the two-hourly frequency distribution is mainly unaffected by local greenhouse gas fluxes, was successful in eliminating the most prominent influences on $\mathrm{CH}_{4}$ mixing ratios imposed by the local farmstead.

\section{S3 Analyzing Mixing Ratio Differences}

25 In order to find the most likely predictor variables that influence the mixing ratio difference between the FRU (mountain-top) and BER (tall-tower) sites, we carried out a principal component analysis 


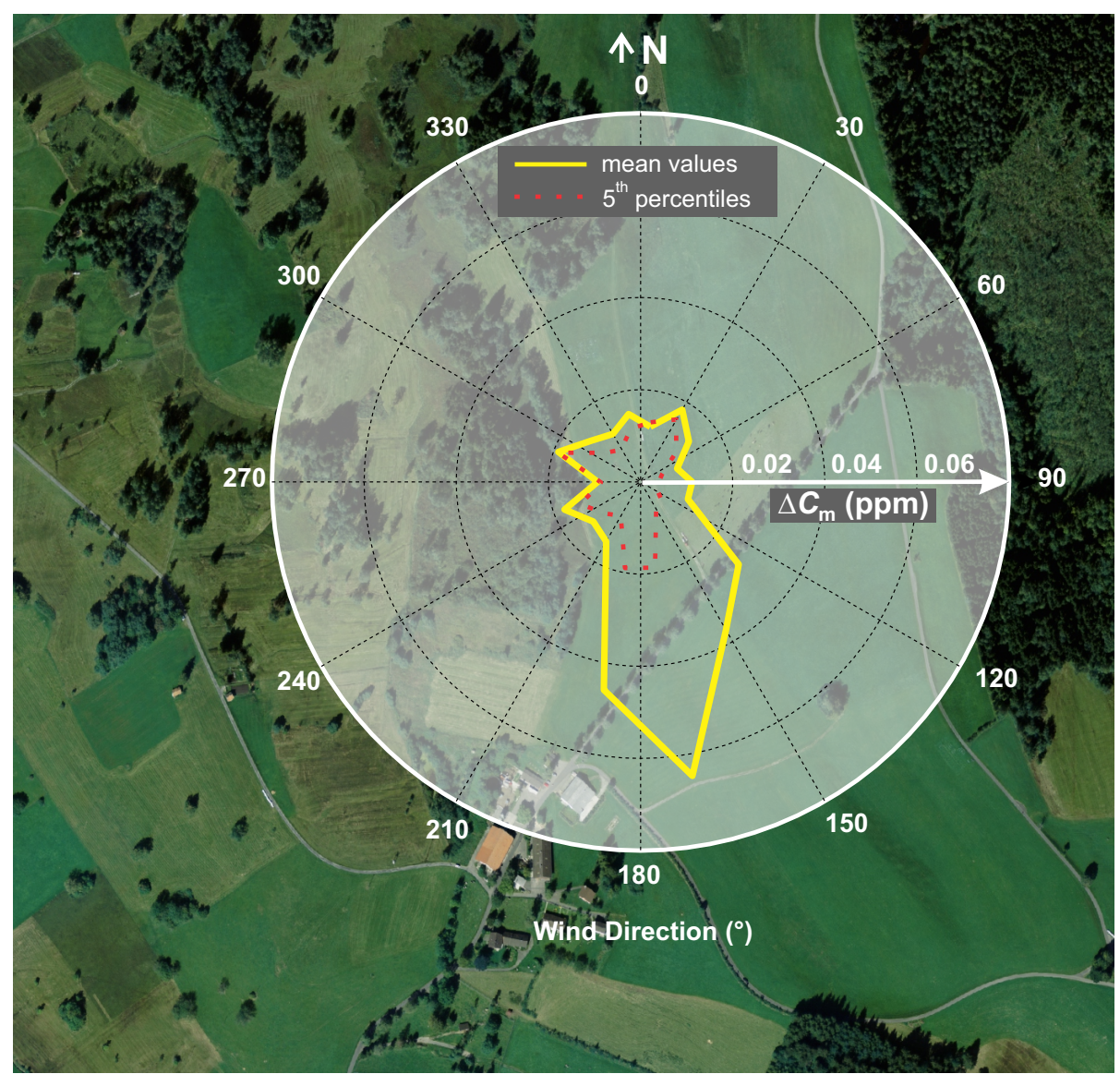

Fig. S1 Binned averages of the $\mathrm{CH}_{4}$ differences between the FRU mountain-top station and the BER tall-tower station $\left(\Delta C_{m}\right)$ as calculated from the annual time series of 2-h averages (yellow line) and the $5^{\text {th }}$ percentiles of the 2-h frequency distribution (red dotted line) for $20^{\circ}$ bins of the wind direction at the mountain top, overlaid on an orthoimage (c) 2014 swisstopo (JD100042) of the mountaintop site

(not shown) to detect collinearities among the meteorological variables that have the potential to predict such differences, and then performed an analysis of variance to determine, which groups of environmental conditions can be used to classify mixing ratio differences between FRU and BER.

All statistical analyses were done with $\mathrm{R}$ (R Core Team, 2016).

The response variables of interest were $\Delta C_{m}$ and $\Delta C_{c}$, the absolute differences in $\mathrm{CH}_{4}$ and $\mathrm{CO}_{2}$ mixing ratio measurements, respectively, measured at the two sites. Positive values of $\Delta C_{m}$ and $\Delta C_{c}$ indicate that the respective gas mixing ratio measured at the FRU mountain-top site exceeded the concurrent measurements at the top of the BER tall-tower site.

\section{S3.1 Analysis of Variance}

\section{S3.1.1 Material and Method}

We carried out an analysis of variance to quantify the differences between the FRU and BER mixing ratio measurements. The goal was not primarily to determine the offset between the sites, but how this potential offset varies with the variables used in the principal component analysis. We used a

40 three-step procedure that takes into account that different variables are most relevant for $\Delta C_{m}$ than for $\Delta C_{c}$ :

1. A five-factorial analysis of variance was computed with the variables wind direction $(\vartheta)$, horizontal wind speed $(U)$, atmospheric stability ( $z / L$; all measured at FRU), $H_{r}$ (hour of day), 
and $S_{n}$ (season, starting with 12 levels corresonding to calender months). To simplify calculations, all variables were binned to classes to reduce the number of levels. In the first step no interactions between the different variables were considered. The $H_{r}$ variable was binned at 2-h resolution, and atmospheric stability was aggregated to the three classes "unstable" $(z / L<-$ $0.0625)$, "neutral" $(-0.0625 \leq z / L<0.0625)$, and "stable" $(z / L \geq 0.0625)$, since both $z / L$ and $L / z$ only showed a weak effect in both principal component analyses for $\Delta C_{m}$ and $\Delta C_{c}$. Wind speed was binned into classes at intervals of $1 \mathrm{~m} \mathrm{~s}^{-1}$, and $\vartheta$ (as measured at the FRU site) was binned in $10^{\circ}$ segments. Tukey's honest significant difference test was calculated on all groupwise comparisons of mixing ratio differences.

2. After this, the classes without significant in-between differences were combined to reduce the number of classes in each variable. $U$ was aggregated to five classes $\left(0-1 \mathrm{~m} \mathrm{~s}^{-1}, 1-2 \mathrm{~m} \mathrm{~s}^{-1}\right.$, $2-5 \mathrm{~m} \mathrm{~s}^{-1}, 5-6 \mathrm{~m} \mathrm{~s}^{-1},>6 \mathrm{~m} \mathrm{~s}^{-1}$ for $\Delta C_{m}$, and $<1 \mathrm{~m} \mathrm{~s}^{-1}, 1-2 \mathrm{~m} \mathrm{~s}^{-1}, 2-4 \mathrm{~m} \mathrm{~s}^{-1}, 4-6 \mathrm{~m} \mathrm{~s}^{-1}$, $>6 \mathrm{~m} \mathrm{~s}^{-1}$ for $\left.\Delta C_{c}\right) . \vartheta$ was aggregated to three classes $\left(70-120^{\circ}, 120-200^{\circ}, 200-70^{\circ}\right)$. To use a more detailed resolution of $H_{r}$ and $S_{n}$ than in Fig. 8, an aggregation was done as shown in Fig. S2 with four classes each for $H_{r}$ and $S_{n}$.

3. With this reduced set of classes a full analysis of variance model including interactions was run. Using stepwise exclusion, all nonsignificant variables and interactions (adjusted $p \geq 0.05$ ) were subsequently eliminated from the model. Within a few iterations we were left with a simplified analysis of variance model that only contained variables and interactions that showed a nonzero influence on measured $\Delta C_{m}$ or $\Delta C_{c}$, respectively, at adjusted $p<0.05$ (see Tables $\mathrm{S} 2 \& \mathrm{~S} 3$ ).

\section{S3.1.2 Results}

On average the mixing ratio offset between FRU and BER was $0.019 \pm 0.019 \mathrm{ppm}$ for $\Delta C_{m}$, and $2.9 \pm 3.7 \mathrm{ppm}$ for $\Delta C_{c}$ (mean difference \pm standard deviation of all group comparison of the groups that were used in the final analysis of variance model).

\section{Differences in $\mathrm{CH}_{4}$ mixing ratios.}

In the first step (no interactions considered) an aggregation of predictor classes was possible, namely be reduced to two classes: 0800-1600 UTC (day), and 2000-0400 UTC (night). Transition times were not included in the analysis. The 12 months of $S_{n}$ could be aggregated to four seasons, January, February-July, August, and September-December. January and August differed in all comparisons with other months, hence this site-specific classification was chosen (Fig. S2). Wind speed classes could be reduced to five classes, and $\vartheta$ was aggregated to three classes (see 75 above). The two stability groups "unstable" and "neutral" did not differ significantly and thus were combined. These classes were used in step 3 to obtain the final analysis of variance Table S2.

The output from the final analysis of variance model (Table S2) was then used to compute group averages, standard deviations, and standard error of the mean of $\Delta C_{m}$ to quantify the possible local effects on $\Delta C_{m}$. These averages were then ranked and plotted in Fig. S3 in combination with the o predictor classes involved.

Figure S3 shows quite clearly that wind directions from $120-200^{\circ}$ were mostly responsible for the largest positive deviations, i.e., local emissions at FRU increase $\mathrm{CH}_{4}$ mixing ratios above the value expected at BER. Contrastingly, the most negative deviations are associated with the highest wind speeds and with the early season (February to July).

Wind directions from $70-120^{\circ}$ (Bise winds; Wanner and Furger, 1990) never led to significantly increased $\Delta C_{m}$ compared to other factor combinations, and hence those wind directions can be considered representative for BER conditions, irrespective of $H_{r}, S_{n}, U$, and $z / L$. Whereas stability, $U$, and $H_{r}$ had a similar influence on the variability of $\Delta C_{m}$ ( $F$ ratios in the range 40-50, Table S2), only $U$ showed a distinct influence on average $\Delta C_{m}$. While weak winds led to positive $\Delta C_{m}$, strong winds were usually associated with negative $\Delta C_{m}$. Thus, $U-$ which is also related to stability - had a much stronger influence than stability on local anomalies in $\mathrm{CH}_{4}$ mixing ratio measurements at FRU. 

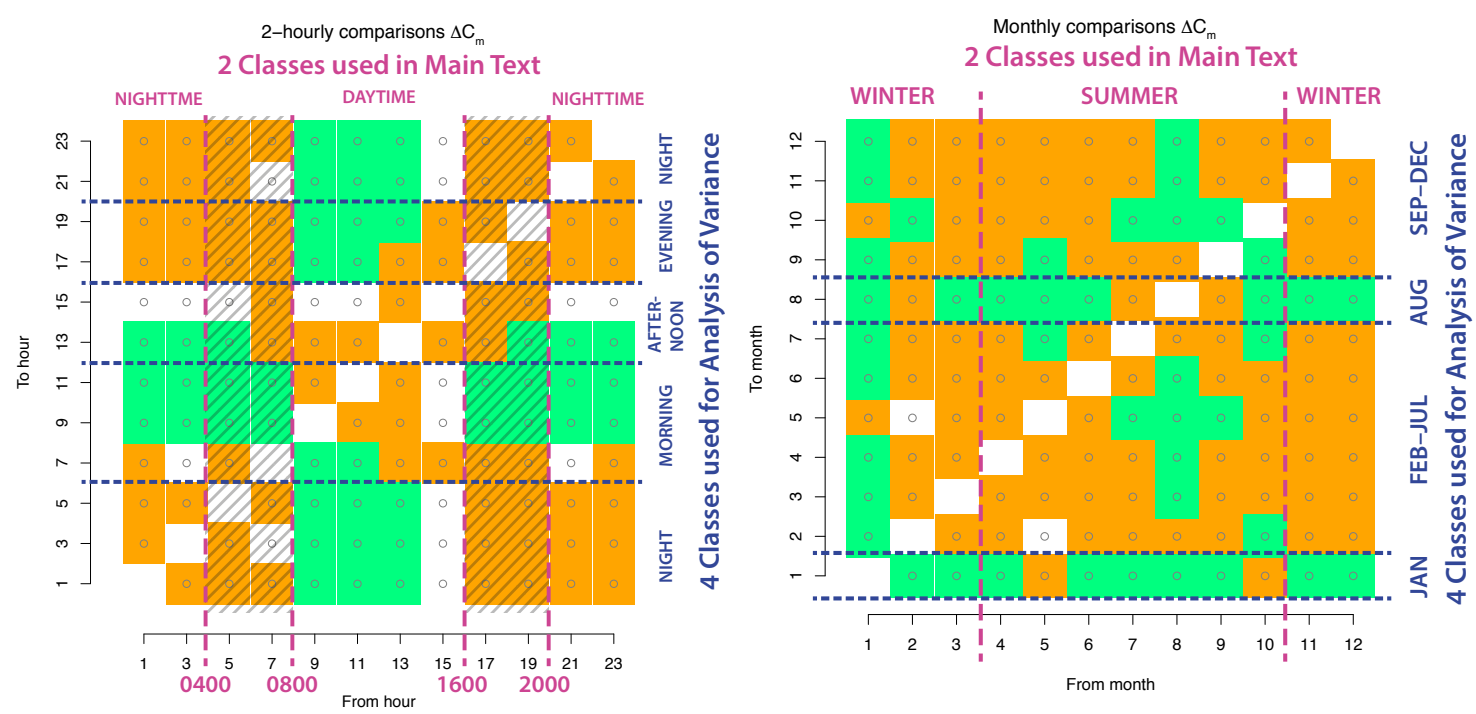

Fig. S2 Aggregation of hour of day $\left(H_{r}\right.$, left) and season $\left(S_{n}\right.$, right) for the analysis of variance of $\mathrm{CH}_{4}$ mixing ratio differences. Both panels show a graphical matrix of pairwise comparisons of $\mathrm{CH}_{4}$ mixing ratio differences. Orange cells denote that Tukey's honest significant difference test yielded an adjusted $p>0.05$, whereas green cells show highly significant differences (adjusted $p<0.01$ ). White cells are either significant in the range $0.01 \leq$ adjusted $p \leq 0.05$, or are the diagonal of the matrix which is ignored. The vertical dashed lines show the coarse separation of the classes used in Fig. 8, whereas the horizontal dashed lines show the separations between classes used in this additional analysis of variance (Fig. S3 and Table S2). The hashed areas are the transition times that are excluded in the analysis for Fig. 8, but are included in the analysis of variance Table S2

Mean $\Delta C_{m}$ was $0.019 \pm 0.019 \mathrm{ppm}$, shown in Fig. S3 with the two dashed vertical lines. The most positive $\Delta C_{m}$ ranged up to $0.060 \mathrm{ppm}$ (January, neutral $z / L$, calm winds $<1 \mathrm{~m} \mathrm{~s}^{-1}$, and $\vartheta$ $120-200^{\circ}$ ), and the most negative $\Delta C_{m}$ was $-0.045 \mathrm{ppm}$ (afternoons with relatively strong winds with $U$ in the range $7-8 \mathrm{~m} \mathrm{~s}^{-1}$ ).

Differences in $\mathrm{CO}_{2}$ mixing ratios.

For $\Delta C_{c}$ the aggregation of the variables led to slightly different classes than for $\Delta C_{m}$. For simplicity we used the same $H_{r}$ classes as for $\mathrm{CH}_{4}$ (night 2000-0600 UTC, morning 0600-1200 UTC,

Table S2 Analysis of variance table for the response variable $\Delta C_{m}$ after stepwise elimination of nonsignificant predictors and predictor combinations, sorted by $F$ value

\begin{tabular}{lrrrrrr}
\hline Factor Interaction & Df & Sum Sq & Mean Sq & $F$ value & $\operatorname{Pr}(>F)$ & \\
\hline$\vartheta$ & 2 & 0.6538 & 0.32691 & 249.6591 & $<2.2 \cdot 10^{-16}$ & $* * *$ \\
$z / L$ & 1 & 0.0648 & 0.06476 & 49.4552 & $2.398 \cdot 10^{-12}$ & $* * *$ \\
$U$ & 7 & 0.3946 & 0.05638 & 43.0564 & $<2.2 \cdot 10^{-16}$ & $* * *$ \\
$H_{r}$ & 3 & 0.1575 & 0.05249 & 40.0872 & $<2.2 \cdot 10^{-16}$ & $* * *$ \\
$S_{n}$ & 3 & 0.1117 & 0.03724 & 28.4392 & $<2.2 \cdot 10^{-16}$ & $* * *$ \\
$\vartheta: U$ & 6 & 0.0728 & 0.01213 & 9.2623 & $4.227 \cdot 10^{10}$ & $* * *$ \\
$\vartheta: z / L$ & 2 & 0.0211 & 0.01054 & 8.0496 & 0.0003247 & $* * *$ \\
$S_{n}: H_{r}$ & 9 & 0.0477 & 0.00530 & 4.0448 & $3.561 \cdot 10^{-5}$ & $* * *$ \\
$\vartheta: H_{r}$ & 6 & 0.0249 & 0.00415 & 3.1680 & 0.0042138 & $* *$ \\
$\vartheta: S_{n}: U$ & 23 & 0.0703 & 0.00306 & 2.3333 & 0.0003198 & $* * *$ \\
$\vartheta: H_{r}: z / L$ & 9 & 0.0238 & 0.00265 & 2.0236 & 0.0330805 & $*$ \\
$\vartheta: S_{n}: H_{r}$ & 23 & 0.0504 & 0.00219 & 1.6732 & 0.0230944 & $*$ \\
Residuals & 3783 & 4.9535 & 0.00131 & & & \\
\hline
\end{tabular}

Asterisks in the last column indicate $p<0.001(* * *), p<0.01(* *)$, and $p<0.05(*)$, and the colons in the first column indicate interactions among variables. The following classes were built for each variable: wind direction $\vartheta 70-120^{\circ}, 120-200^{\circ}, 200-70^{\circ}$; wind speed $U<1 \mathrm{~m} \mathrm{~s}^{-1}, 1-2 \mathrm{~m} \mathrm{~s}^{-1}, 2-5 \mathrm{~m} \mathrm{~s}^{-1}, 5-6 \mathrm{~m} \mathrm{~s}^{-1}$, $>6 \mathrm{~m} \mathrm{~s}^{-1}$; hour of day $H_{r}$ 0600-1200 (morning), 1200-1600 (afternoon), 1600-2000 (evening), 2000-0600 (night); season $S_{n}$ January, February-July, August, September-December; stability $z / L$ stable, unstable and neutral. 


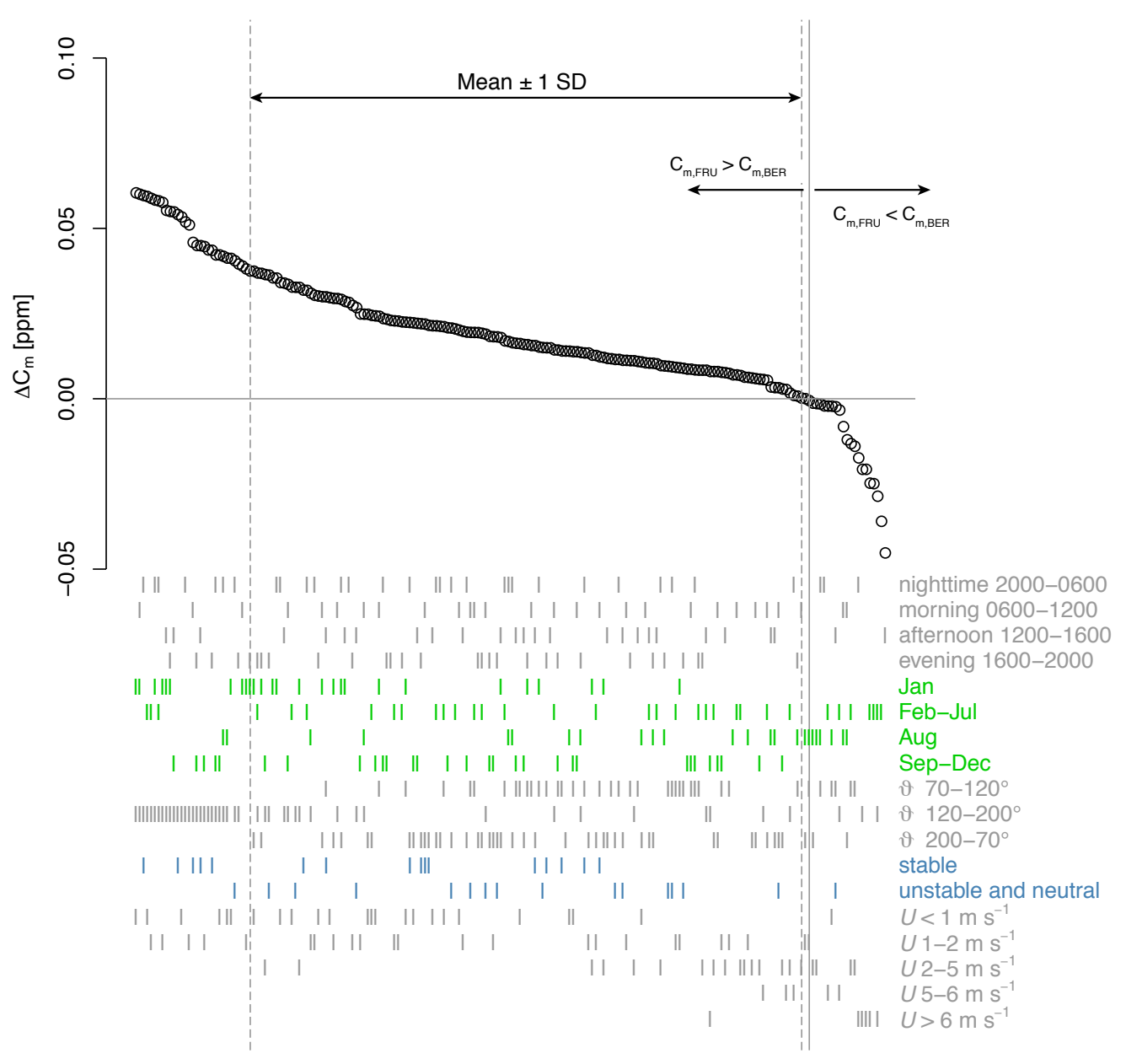

Fig. S3 Group averages of differences in $\mathrm{CH}_{4}$ mixing ratios measured at the FRU site in comparison with the BER site, sorted in descending order. The mean difference \pm one standard deviation (i.e., $0.019 \pm 0.019 \mathrm{ppm}$ ) is shown with two vertical dashed lines. The zero difference is shown with a horizontal and a vertical solid thin line. The vertical symbols below the graph indicate which class combination was used for the respective group average. As a reading example: the most positive values of $\Delta C_{m}$ are found in group comparisons that involve the wind direction sector $120-200^{\circ}$, and the most negative deviations are found at the highest wind speeds

(1600 UTC, evening 1600-2000 UTC), and the transition times (0400-0800 UTC and 1600-2000 UTC) were excluded from further analysis (Fig. S4) in the same way as was done with $\mathrm{CH}_{4}$. Seasonality was represented by four levels: November-April, May-June, July-August, and September-October. For $\vartheta$ we used the same three sectors as for $\mathrm{CH}_{4}: \vartheta 70-120^{\circ}, 120-200^{\circ}$, $200-70^{\circ}$. For $U$ five levels were used: $<1 \mathrm{~m} \mathrm{~s}^{-1}, 1-2 \mathrm{~m} \mathrm{~s}^{-1}, 2-5 \mathrm{~m} \mathrm{~s}^{-1}, 5-6 \mathrm{~m} \mathrm{~s}^{-1}$, and $>6 \mathrm{~m} \mathrm{~s}^{-1}$. is shown in Table $\mathrm{S} 3$.

Similarly to $\Delta C_{m}$ we sorted the differences and plotted the values along with the classes involved (Fig. S5). Beginning at the bottom of Fig. S5 it is quite clearly seen that large positive differences are never associated with wind speeds above $2 \mathrm{~m} \mathrm{~s}^{-1}$, and the most negative deviations are associated with high wind speeds (and thus enhanced turbulent mixing). At the same time, the most negative values of $\Delta C_{c}$ tend to be related to the southeastern wind sector. This wind sector is mostly associated with foehn conditions (Desai et al., 2016), that bring fresh and warm air from the Alps directly to FRU, whereas the BER site actually should already see parts of the anthropogenic emissions in the Alpine foreland. Hence such differences-although weak and only represented by 15 few datapoints - are realistic and most likely true differences, not sampling artefacts. Very positive deviations are primarily associated with nighttime or early morning (dusk), and mostly during 

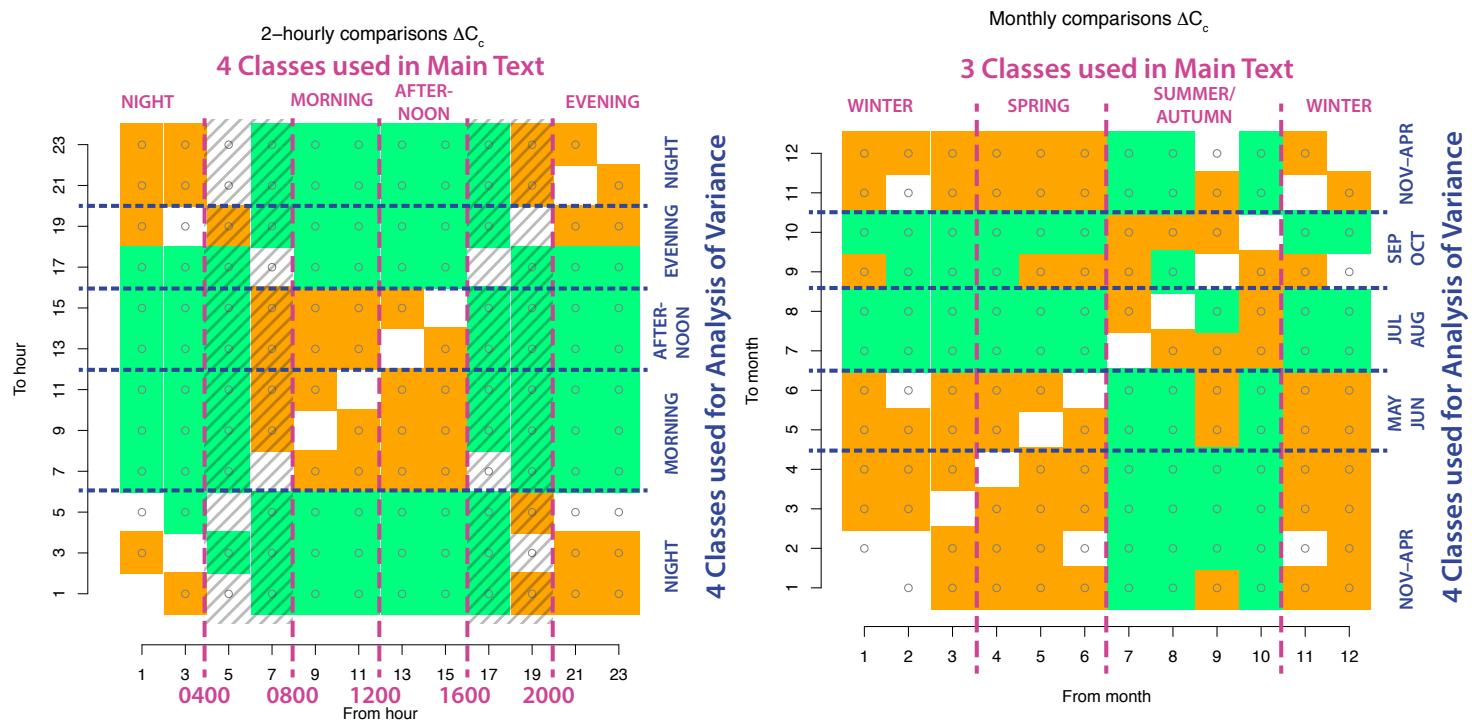

Fig. S4 Aggregation of hour of day $\left(H_{r}\right.$, left) and season $\left(S_{n}\right.$, right) for the analysis of variance of $\mathrm{CO}_{2}$ mixing ratio differences. Both panels show a graphical matrix of pairwise comparisons of $\mathrm{CO}_{2}$ mixing ratio differences. Orange cells denote that Tukey's honest significant difference test yielded an adjusted $p>0.05$, whereas green cells show highly significant differences $(p<0.01)$. The vertical dashed lines show the coarse separation of the classes used in Fig. 9, whereas the horizontal dashed lines show the separations between classes used in this additional analysis of variance (Fig. S5 and Table S3). The hashed areas are the transition times that are excluded in the analysis for Fig. 9, but are included in the analysis of variance Table S3. White cells are either the diagonal of the matrix or differences in the range $0.01<p \leq 0.05$

Table S3 Analysis of variance table for the response variable $\Delta C_{c}$ after stepwise elimination of nonsignificant predictors and predictor combinations, sorted by $F$ value

\begin{tabular}{lrrrrrr}
\hline Factor Interaction & Df & Sum Sq & Mean Sq & $F$ value & $\operatorname{Pr}(>F)$ & \\
\hline$H_{r}$ & 3 & 20553 & 6851.2 & 363.5365 & $<2.2 \cdot 10^{-16}$ & $* * *$ \\
$\vartheta$ & 2 & 8716 & 4357.8 & 231.2329 & $<2.2 \cdot 10^{-16}$ & $* * *$ \\
$U$ & 4 & 7569 & 1892.3 & 100.4102 & $<2.2 \cdot 10^{-16}$ & $* * *$ \\
$S_{n}$ & 3 & 5265 & 1755.2 & 93.1325 & $<2.2 \cdot 10^{-16}$ & $* * *$ \\
$z / L$ & 2 & 2767 & 1383.3 & 73.4019 & $<2.2 \cdot 10^{-16}$ & $* * *$ \\
$S_{n}: H_{r}$ & 9 & 7604 & 844.9 & 44.8299 & $<2.2 \cdot 10^{-16}$ & $* * *$ \\
$\vartheta: S_{n}$ & 6 & 4141 & 690.1 & 36.6186 & $<2.2 \cdot 10^{-16}$ & $* * *$ \\
$H_{r}: z / L$ & 6 & 699 & 116.5 & 6.1814 & $1.823 \cdot 10^{-6}$ & $* * *$ \\
$H_{r}: U$ & 12 & 893 & 74.4 & 3.9496 & $4.379 \cdot 10^{-6}$ & $* * *$ \\
$S_{n}: U$ & 11 & 778 & 70.8 & 3.7547 & $2.296 \cdot 10^{-5}$ & $* * *$ \\
$\vartheta: H_{r}$ & 6 & 376 & 62.6 & 3.3243 & 0.002882 & $* *$ \\
$\vartheta: S_{n}: H_{r}$ & 16 & 710 & 44.4 & 2.3547 & 0.001751 & $* *$ \\
$\vartheta: S_{n}: U$ & 19 & 768 & 40.4 & 2.1435 & 0.002731 & $* *$ \\
$S_{n}: H_{r}: z / L$ & 16 & 615 & 38.4 & 2.0390 & 0.008491 & $* *$ \\
$\vartheta: H_{r}: z / L$ & 12 & 436 & 36.3 & 1.9285 & 0.026884 & $*$ \\
$\vartheta: S_{n}: z / L$ & 22 & 794 & 36.1 & 1.9150 & 0.006244 & $* *$ \\
$\vartheta: S_{n}: z / L: U$ & 51 & 1564 & 30.7 & 1.6275 & 0.003339 & $* *$ \\
$\operatorname{Residuals}$ & 3689 & 69522 & 18.8 & & & \\
\hline
\end{tabular}

Asterisks in the last column indicate $p<0.001$ (***), $p<0.01(* *)$, and $p<0.05(*)$, and the colons in the first column indicate interactions among variables. The following classes were built for each variable: wind direction $\vartheta 70-120^{\circ}, 120-200^{\circ}$, and $200-70^{\circ}$; wind speed $U<1 \mathrm{~m} \mathrm{~s}^{-1}, 1-2 \mathrm{~m} \mathrm{~s}^{-1}, 2-4 \mathrm{~m} \mathrm{~s}^{-1}, 4-6 \mathrm{~m} \mathrm{~s}^{-1},>6 \mathrm{~m} \mathrm{~s}^{-1}$; hour of day $H_{r}$ 0600-1200 (morning), 1200-1600 (afternoon), 1600-2000 (evening), 2000-0600 (night); season $S_{n}$ November-March, April-June, July-August, September-October; stability $z / L$ stable, neutral, unstable.

the warm season from July until October. This coincides with the period when the vegetation is most active during the day. At the same time soils are warm enough to enhance the activity of soil microbes that decompose soil organic matter and increase the local $\mathrm{CO}_{2}$ mixing ratio, namely at night. The largest positive $\Delta C_{c}$ observed was $14.3 \mathrm{ppm}$ (July-August, neutral $z / L$, calm winds 


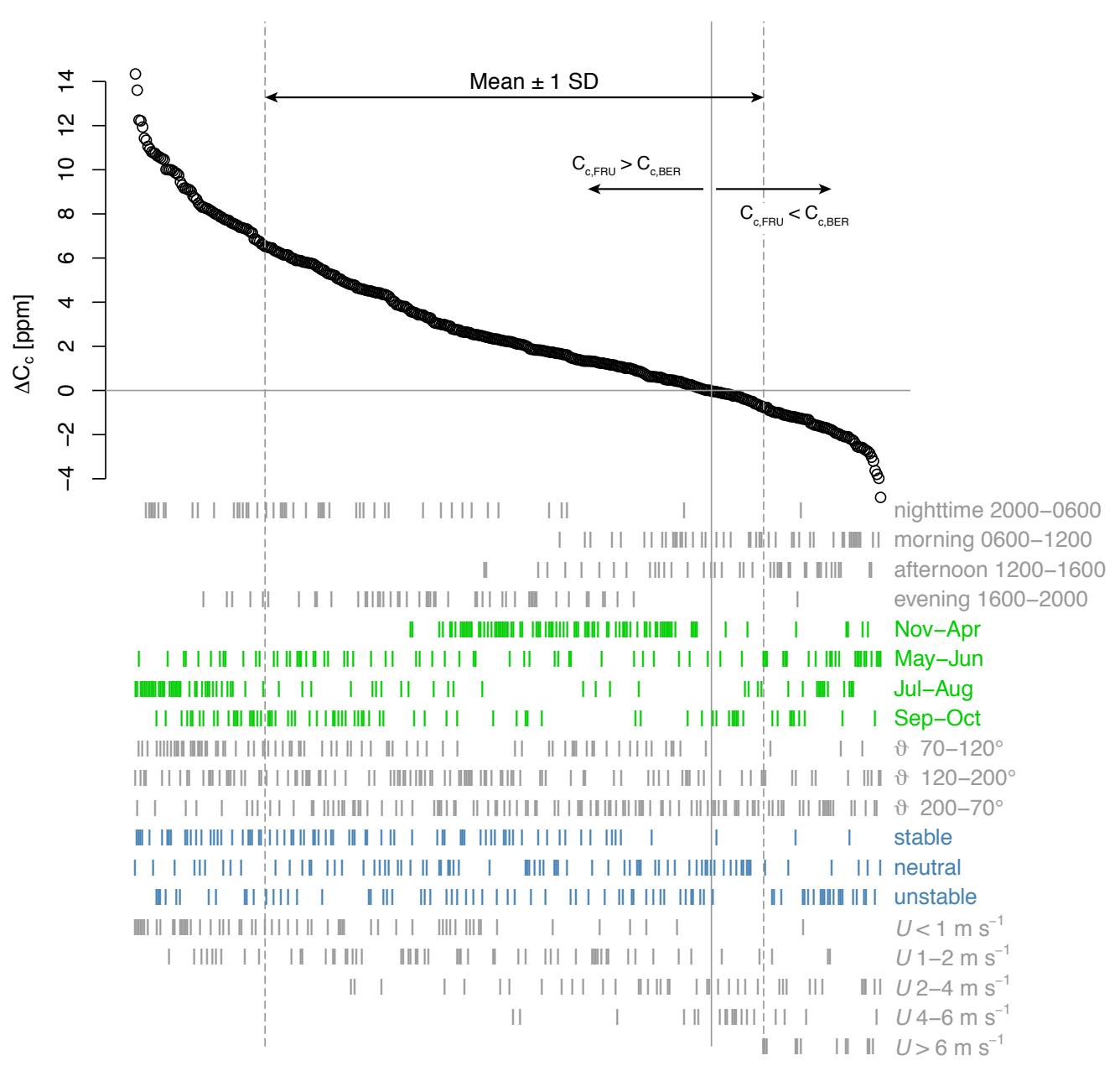

Fig. S5 Group means of differences in $\mathrm{CO}_{2}$ mixing ratios measured at the FRU site in comparison with the BER site, sorted in descending order. Only group comparisons with statistically significant nonzero differences $(p<0.05)$ are shown. The mean difference \pm one standard deviation (i.e., $2.9 \pm 3.7 \mathrm{ppm}$ ) is shown with two vertical dashed lines. The zero difference is shown with a horizontal and a vertical solid thin line. The vertical symbols below the graph indicate which class combination was used for the respective group mean

$<1 \mathrm{~m} \mathrm{~s}^{-1}$, and $\vartheta 120-200^{\circ}$ ), and the most negative value was $-4.8 \mathrm{ppm}$ (May-June, neutral $z / L$, $U 2-4 \mathrm{~m} \mathrm{~s}^{-1}$, and $\vartheta 120-200^{\circ}$ ).

\section{References}

Desai AR, Wohlfahrt G, Zeeman MJ, Katata G, Eugster W, Montagnani L, Gianelle D, Mauder M, Schmid HP (2016) Montane ecosystem productivity responds more to global circulation patterns than climatic trends. Environ Res Lett 11:024,013, DOI 10.1088/1748-9326/11/2/024013

R Core Team (2016) R: A Language and Environment for Statistical Computing. R Foundation for Statistical Computing, Vienna, Austria, URL https://www.R-project.org/

Wanner H, Furger M (1990) The Bise - Climatology of a regional wind north of the Alps. Meteorol Atmos Phys 43:105-115, DOI 10.1007/BF01028113 